\title{
Real-scale chlorination of BW30 TFC membranes and their physicochemical characterization
}

Rhea Verbeke, ${ }^{\mathrm{a}}$ Veronica Gomez, ${ }^{\mathrm{b}}$ Tönjes Koschine, ${ }^{\mathrm{a}}$ Sam Eyley, ${ }^{\mathrm{c}}$ Anthony Szymczyk, ${ }^{\mathrm{d}}$ Marcel Dickmann, ${ }^{\mathrm{e}}$ Tanja Stimpel-Lindner, ${ }^{\mathrm{f}}$ Werner Egger, ${ }^{\mathrm{g}} \mathrm{Wim}$ Thielemans, ${ }^{\mathrm{c}}$ Ivo Vankelecom ${ }^{\mathrm{a}}$

${ }^{a}$ Centre for Surface Chemistry and Catalysis, Faculty of Bioengineering Sciences, KU Leuven, Celestijnenlaan 200F, PO Box 2461, 3001 Leuven, Belgium

${ }^{\mathrm{b}}$ Dow Water and Process Solutions, Autovía Tarragona-Salou s/n, 43006 Tarragona, Spain

${ }^{\mathrm{c}}$ Chemical Engineering, KU Leuven Campus Kulak Kortrijk, Etienne Sabbelaan 53 box 7659, 8500 Kortrijk, Belgium

${ }^{d}$ Institut des Sciences Chimiques de Rennes, CNRS, UMR 6226, Université de Rennes 1, 35042 Rennes, France

e Heinz Maier-Leibnitz Zentrum (MLZ) and Physik Department E21, Technische Universität München, Lichtenbergstraße 1, 85748 Garching, Germany

${ }^{f}$ Institut für Physik, Universität der Bundeswehr München, Werner-Heisenberg-Weg 39, 85577 Neubiberg, Germany

g Institut für Angewandte Physik und Messtechnik, Universität der Bundeswehr München, 85577 Neubiberg, Germany

*Corresponding author at: Centre for Surface Chemistry and Catalysis, Faculty of

Bioengineering Sciences, KU Leuven, Celestijnenlaan 200F, PO Box 2461, 3001 Leuven,

Belgium.

E-mail address: ivo.vankelecom@kuleuven.be

\begin{abstract}
Chlorination remains a big hurdle in membrane technology as the most commonly used membranes for water purification consist of a polyamide top-layer, which is not fully resistant towards chlorine-induced oxidation. In this work, DOW FILMTEC ${ }^{\mathrm{TM}}$ BW30 membrane elements were systematically chlorinated with $\mathrm{NaOCl}$ at pilot-scale under acidic conditions (pH4) at 10 bar for $2.5 \mathrm{~h}$. Variations in membrane performance and their physicochemical properties were determined by ATR-FTIR, XPS, WD-XRF, SEM, AFM and zeta-potential measurements. With increasing bleaching concentration, both membrane roughness and chlorine incorporation via N- and ring-chlorination increased, while surface charge remained quasi unaltered. Both water flux and salt passage decreased proportionally over the whole concentration range. Accordingly, positron annihilation lifetime spectroscopy (PALS) revealed a decrease in the size of the top-layer free-volume elements as chlorine concentration increased, confirming, for the first time in a quantitative manner, the so-called tightening effect. The obtained results also show that thin-film composite (TFC) membranes are altered differently when chlorinated under pressure than via simple immersion, as conventionally performed in literature.
\end{abstract}

Keywords: active chlorination, pilot-scale, polyamide, PALS, tightening effect

C 2018. This manuscript version is made available under the CC-BY-NC-ND 4.0 license http://creativecommons.org/licenses/by-nc-nd/4.0/

The final published version of this article is available at http://dx.doi.org/10.1016/j.memsci.2018.01.019 


\section{Introduction}

Climate change and population growth, together with human and industrial activities, exert increasing stress on the existing water supplies [1]. The impetus to find solutions to meet the increasing water demand, expected to grow by $55 \%$ globally in 2050 , has never been bigger [2]. Membrane-based treatment technologies currently play a major role in water purification as they can tackle different water sources, produce high quality water and leave a smaller footprint, compared to conventional separation technologies [3].

The so-called thin film composite (TFC) membranes dominate the water industry as they can concurrently achieve salt retentions up to $99.8 \%$ and high water permeances. Their polyamide (PA) top-layers of $<200 \mathrm{~nm}$ are responsible for the actual membrane performance, but are also the primordial source of concern due to their high reactivity towards oxidizing agents (e.g. chlorine species). The proposed general mechanism of PA chlorination is shown in Figure 1. The poor chlorine-resistance of PA-membranes is due to the sensitivity of the amidic nitrogen to $\mathrm{Cl}$-attack. Other reactions (i.e. ring-chlorination, Orton rearrangement and hydrolysis), which occur after this N-chlorination reaction, lead to further membrane failure [4].

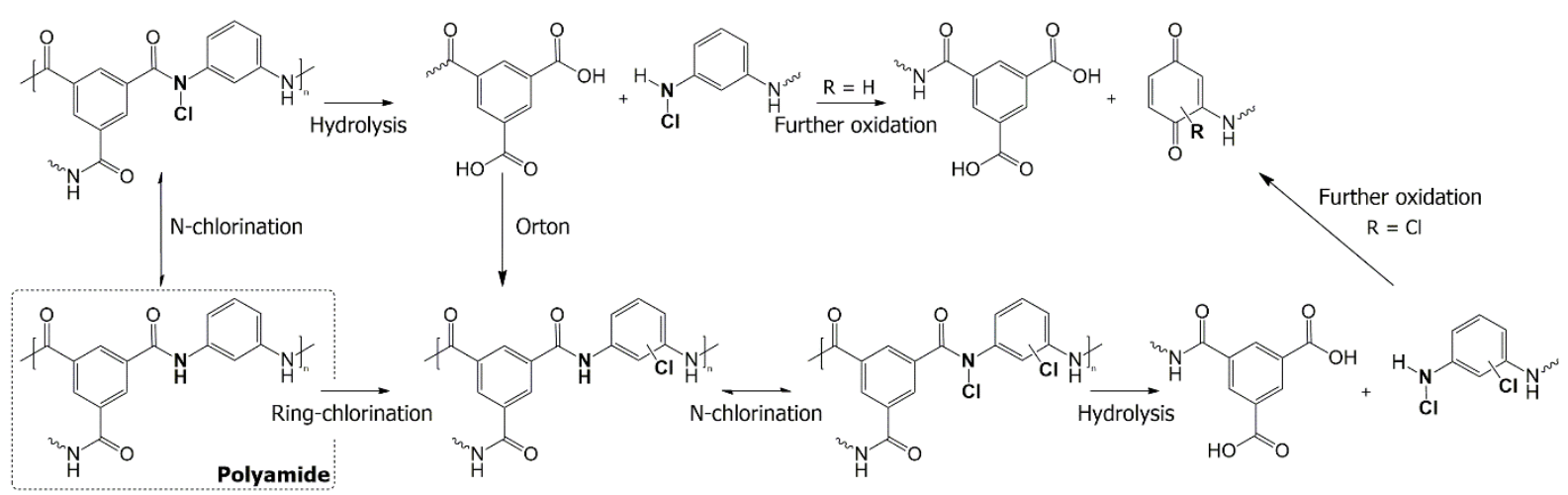

Figure 1: Proposed general mechanism of chlorine attack on polyamide: N-chlorination, direct ring-chlorination, Orton rearrangement, and hydrolysis [4].

At industrial scale, chlorination is a standard procedure to prevent bio-fouling by inactivating micro-organisms. Because reverse osmosis (RO)/ nanofiltration (NF)-membranes typically show only 200-1000 h tolerance to $1 \mathrm{ppm}$ chlorine [5], residual free chlorine has to be removed completely when these membranes are used in downstream processes. Continuous and complete free chlorine removal may be impeded by various practical factors in the operation of a treatment plant [5-7], causing trace amounts of chlorine to reach and hence attack the PA active layer. Degradation of membrane integrity, and ultimately performance, then leads to the unavoidable replacement of full elements.

The reactions depicted in Figure 1 occur under different conditions and are known to be influenced by many parameters, such as temperature, $\mathrm{pH}$ and chlorine concentration, as well as by the presence of bromide and metal ions [8-11]. Nonetheless, their exact effect on membrane integrity and performance remains unclear. Contradicting findings on rejection, permeate flux, membrane surface charge and wettability are often reported. This is possibly due to the use of different experimental set-ups and chlorine exposure conditions $[8,12-15]$. Two reviews on the chlorine-resistance of PA TFC membranes and the factors influencing it, were recently published $[4,16]$. For example, chlorination can be done in passive mode, by immersing the membrane or recirculating it in a chlorine solution at atmospheric pressure, or it can be done in active mode, where the chlorination step is executed under pressure. Additionally, the ppm $\cdot h$ 
concept fails to accurately describe chlorine exposure. Nevertheless, the comprehensive investigations of Do et al. concluded that at low $\mathrm{pH}$, chlorine incorporation dominates, while under alkaline conditions, chlorine-promoted hydrolysis prevails. Their consistent results for passive chlorination are represented in Figure 2.

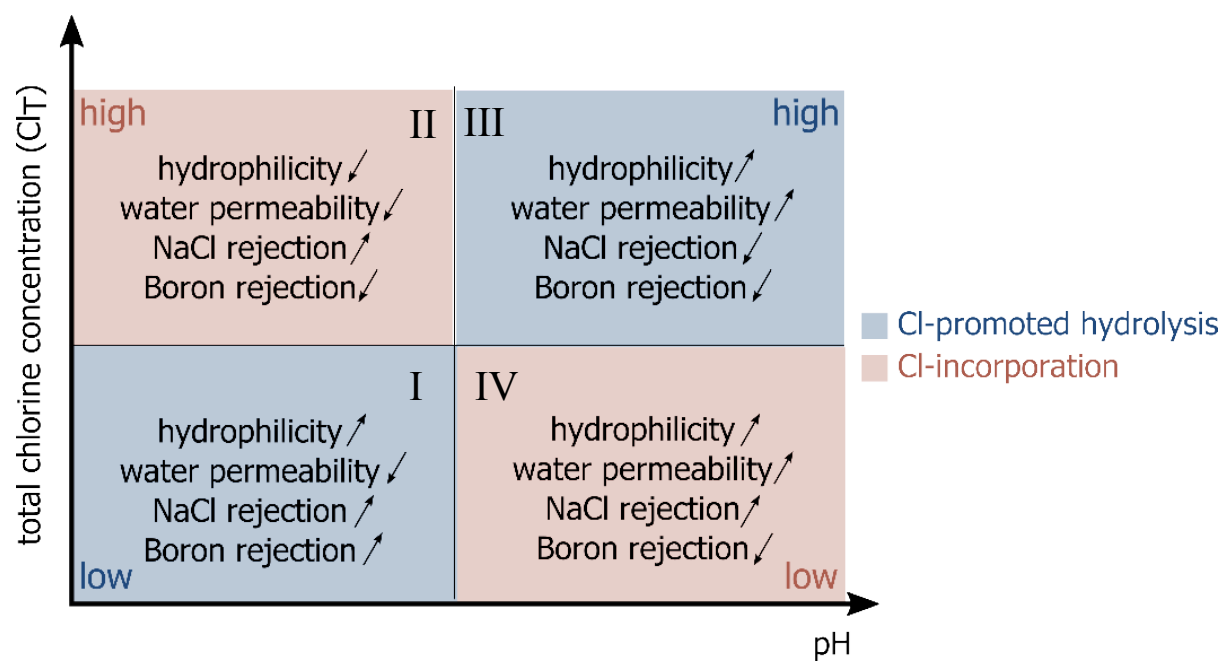

Figure 2: Main effects of $\mathrm{pH}$ and chlorine concentration on membrane performance and characteristics, adapted from [14].

To bridge the gap between accelerated lab-scale chlorination and the accidental chlorination in a water-treatment plant, we herein report the systematic investigation of the effect of low concentrations of sodium hypochlorite $(\mathrm{NaOCl})$ on a typical polyamide $(\mathrm{PA}) \mathrm{RO}$ membrane at acidic $\mathrm{pH}$. Only two pilot-scale studies introducing a chlorination step have been reported so far, of which one was executed via immersion, rather than under pressure [13,17]. Therefore, the aim of this study was to investigate the implications of chlorination at large scale on the performance as well as on the nanoscale characteristics (e.g. elemental composition, membrane morphology, surface charge) of a commercial RO TFC PA membrane, containing a removable coating layer. This further enabled the possibility to examine whether results from lab-scale chlorination trials can be extrapolated to unwanted chlorination in industry. Additionally, to establish a better, more fundamental, understanding of the effect of chlorine-attack on PA membranes, changes in the free-volume were determined via positron annihilation lifetime spectroscopy (PALS), for the first time on chlorinated membranes. Additionally, the influence of pressure on the chlorination process was investigated.

\section{Materials and Methods}

\subsection{Membrane}

Commercially available 8" spiral wound elements of brackish water membranes (DOW FILMTEC ${ }^{\text {TM } 1}{ }^{1}$ BW30-400 and BW30-440i elements) were used for this study. BW30 chemistry consist of a fully aromatic polyamide layer with a removable coating layer [18]. A reference flat sheet BW30 membrane was used as reference for X-ray fluorescence measurements.

\subsection{Chemicals}

Sodium chloride $(\mathrm{NaCl}, \mathrm{VWR})$, boric acid $\left(\mathrm{B}(\mathrm{OH})_{3}, 4 \%\right.$, VWR) and isopropanol (IPA, GC grade, MERCK) were used as solutes. Sodium hypochlorite (NaOCl, 15\%, MERCK) was used

\footnotetext{
${ }^{1}$ Trademark of The Dow Chemical Company ("Dow") or an affiliated company of Dow
} 
as chlorinating agent and the $\mathrm{pH}$ of the feed solution was adjusted to 4 with hydrochloric acid ( $\mathrm{HCl}, 1 \mathrm{M}, \mathrm{MERCK})$. All chemicals were used as received.

\subsection{Filtration and chlorination protocol}

The chlorination of four spiral wound DOW FILMTEC ${ }^{\mathrm{TM}}$ BW30-440i elements was executed at a pilot-plant of the Tarragona Global Water Technology Centre of Dow Water and Process Solutions (DW\&PS) in Tarragona, Spain. At the beginning of each filtration run, the elements were flushed with RO permeate with minimum permeation for the removal of preservation agents, according to the FILMTEC ${ }^{\mathrm{TM}}$ Manual [5]. A summarizing diagram of the filtration and chlorination protocol is given in Figure 3.

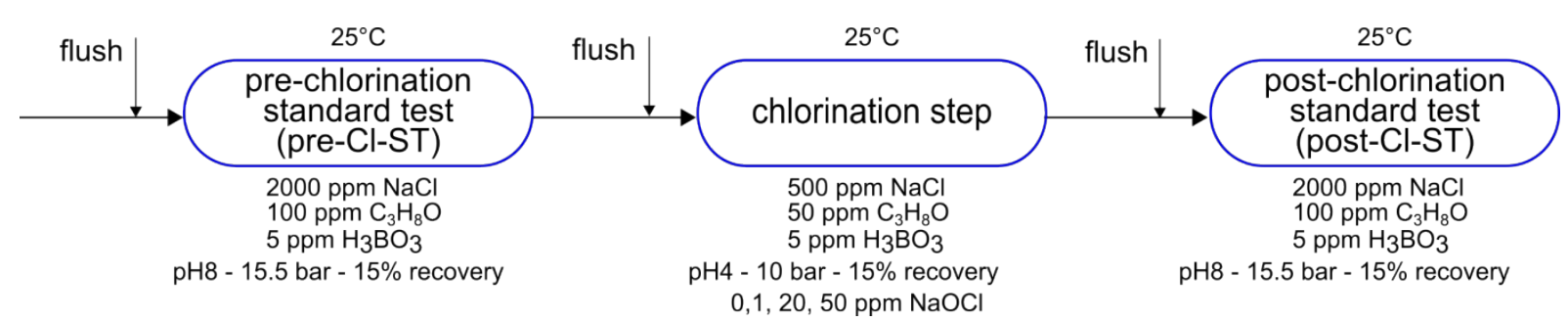

Figure 3: Schematic diagram of the active chlorination protocol of DOW FILMTEC ${ }^{\text {TM }}$ BW30 elements at pilot-scale. All three steps (pre-chlorination standard test, chlorination step, post-chlorination standard test) were executed in recirculation mode.

\subsubsection{Pre- and post-chlorination standard test}

To investigate the influence of chlorine concentration on the membrane performance, a filtration test under DOW FILMTEC ${ }^{\mathrm{TM}}$ BW30 element Standard Test Conditions [5] was performed before (pre-chlorination standard test (pre-Cl-ST)) and after (post-chlorination standard test, (post-Cl-ST)) the chlorination step. Both tests were executed at $15.5 \mathrm{bar}, 25{ }^{\circ} \mathrm{C}$, $\mathrm{pH} 8$ and at a constant recovery of $15 \%$ in a closed system. The applied pressure, the membrane permeate flow and feed and permeate conductivities were continuously monitored by on-line measurements. The feed consisted of $\mathrm{RO}$ permeate, spiked with $\mathrm{NaCl}(2000 \mathrm{ppm})$, iso-propanol (IPA) $(100 \mathrm{ppm})$ and boric acid (5 ppm). The latter two were added to investigate the rejection of neutral solutes, compared to the charged salt $\mathrm{NaCl}$. Samples of the feed and the permeate streams were taken after reaching steady-state. After the pre-Cl-ST and before the post-Cl-ST, the membrane was flushed with RO permeate during $10 \mathrm{~min}$, in once through mode.

\subsubsection{Chlorination protocol}

\subsubsection{Active chlorination}

The chlorination step was executed for $2.5 \mathrm{~h}$ at $10 \mathrm{bar}$, in recirculation mode. The feed solution consisted of RO permeate with solute concentrations of $500 \mathrm{ppm} \mathrm{NaCl}, 50 \mathrm{ppm}$ IPA and $5 \mathrm{ppm}$ $\mathrm{H}_{3} \mathrm{BO}_{3}$. Lower solute concentrations compared to the pre-Cl-ST and post-Cl-ST were used in order to keep the net-driving pressure similar. The feed solution was spiked with 0 (reference), 1, 20 or $50 \mathrm{ppm} \mathrm{NaOCl}$ and its $\mathrm{pH}$ was lowered to 4 by dosing with $\mathrm{HCl}$. At this $\mathrm{pH}$, the available chlorine is $\pm 100 \% \mathrm{HOCl}$ [14]. The chlorine concentration and $\mathrm{pH}$ was monitored with a portable chlorine meter (AL400, Aqualytic and a bench lab spectrophotometer) and a portable DR5000 meter (Hach). Samples from the feed solution were taken at least 5 times during the $2.5 \mathrm{~h}$ and measured for their chlorine content. The chlorine concentration was adjusted if necessary by dosing with additional $\mathrm{NaOCl}$. The concentrations used in this study $(1,20$ and $50 \mathrm{ppm})$ should hence be seen as average values, since the concentrations slightly varied during the trial due to degradation and/or consumption by the membrane. Evaporation 
of volatile solutes is believed to be minimal as the filtration set-up was only opened to adjust the chlorine concentration of the feed water.

\subsubsection{Passive chlorination}

One element was also chlorinated under passive conditions, i.e. without applying pressure and hence without permeating, by recirculating an aqueous solution of $1 \mathrm{ppm} \mathrm{NaOCl}$ for $2.5 \mathrm{~h}$. One should note that via this procedure only the active layer got contacted with the oxidizing solution, as opposed to immersion via soaking where the whole membrane (i.e. top and support layer) is soaked in the solution. As for active chlorination, samples from the feed water were taken on average every $20 \mathrm{~min}$ and measured for their chlorine concentration (portable clorimeter, AL400 from Aqualytic and bench lab spectrophotometer, DR5000 from Hach). If necessary, additional $\mathrm{NaOCl}$ was added to the feed tank to maintain an average concentration of 1 ppm $\mathrm{NaOCl}$ during the trial.

\subsection{Membrane performance}

The influence of the presence of $\mathrm{NaOCl}$ on membrane performance was determined by comparing the salt passage (SP), or rejection (R) and membrane permeability coefficient A (L $\mathrm{h}^{-1} \mathrm{~m}^{-2}$ bar-1 $^{-1}$ ), after reaching steady-state, of the pre-Cl-ST with the values of the post-Cl-ST. The change in SP, R and A, respectively, is expressed as follows:

$$
\begin{aligned}
\Delta S P & =\frac{S P_{\text {post }}-C l-S T-S P_{\text {pre }}-C l-S T}{S P_{\text {pre }}-C l-S T} \\
\Delta R & =\frac{R_{\text {post }}-C l-S T-R_{\text {pre }}-C l-S T}{R_{\text {pre }}-C l-S T} \\
\Delta A & =\frac{A_{\text {post }}-C l-S T-A_{\text {pre }}-C l-S T}{A_{\text {pre }}-C l-S T}
\end{aligned}
$$

A negative (positive) $\Delta$-value thus indicates a lower (higher) value in the post-Cl-ST than in the pre-Cl-ST. For example, when $\Delta \mathrm{SP}$ equals $-20 \%$, this means that the SP of the post-Cl-ST is $20 \%$ lower than the SP of the pre-Cl-ST.

The SP and $\mathrm{R}$ are determined according to:

$$
R=(1-S P), \text { with } S P={ }^{C} p / C_{f}
$$

where $\mathrm{C}_{\mathrm{p}}$ and $\mathrm{C}_{\mathrm{f}}$ are the solute concentration of the permeate and the feed, respectively. Ion chromatography was used to determine the anion content (HPIC INTEGRION, Dionex), while inductively coupled plasma (ICP) optical emission spectrometry (OES) was used to determine the cation and metal content (Optima 8300, Perkin Elmer). The rejection of IPA was based on total organic carbon (TOC) measurements (TOC-L, Schimadzu). All solute determinations were executed in triplicates. The permeate water flow $\left(\mathrm{Q}_{\mathrm{p}}\right.$, in $\left.\mathrm{L} \mathrm{h}^{-1}\right)$ is recorded online and the membrane permeability coefficient $\mathrm{A}\left(\mathrm{L} \mathrm{h}^{-1} \mathrm{~m}^{-2} \mathrm{bar}^{-1}\right)$ is determined according to:

$$
Q_{p}=A \cdot S \cdot(\Delta P-\Delta \pi)
$$

with $\mathrm{S}$ the wetted surface area $\left(\mathrm{m}^{2}\right)$ and $(\Delta \mathrm{P}-\Delta \pi)$ the net driving pressure (bar). $\Delta \mathrm{P}$ and $\Delta \pi$ are the difference in pressure and osmotic pressure, respectively, between the feed side and the permeate side of the membrane. The reported standard deviations are based on the online recordings of $\mathrm{Q}_{\mathrm{p}}$, after reaching steady state, for at least 20 minutes. 
The obtained raw data from pre- and post-Cl-ST were normalized to a given reference performance, i.e. the designed performance of a BW30 8" membrane module under the applied conditions, following the equations presented in FILMTEC ${ }^{\mathrm{TM}}$ Manual [5]. This is necessary to be able to distinguish between changes in performance due to, on the one hand, the presence of chlorine, and, on the other hand, the influence of the operating parameters (e.g. slight changes in temperature, recovery, feed pressure) [5]. By normalizing the data, the influence of operating parameters is omitted and hence, the changes in membrane performance can be fully related to the influence of chlorine on the membrane.

\subsection{Physico-chemical characterization}

Membrane samples were extracted from the 8" elements, cleaned with DI water and dried before analysis with wavelength-dispersive X-ray fluorescence (WD-XRF), X-ray photoelectron spectroscopy (XPS), attenuated total reflectance Fourier-transform infrared spectroscopy (ATR-FTIR), scanning electron microscopy (SEM), atomic force microscopy (AFM), zeta potential measurements and positron annihilation lifetime spectroscopy (PALS).

\subsubsection{WD-XRF}

WD-XRF spectroscopy was performed at DW\&PS (Tarragona, Spain) with an WD-XRF AXIOS spectrometer from PanAlytical. Spectrum recording and evaluation were performed with a semi-quantitative method, specific for halogens, with pre-calibrated Iq+ standards and treated with Super Q software (PanAlytical). 8 coupons of a flat sheet BW30 membrane were analysed as reference, while all other samples from the 8 " membrane modules were analysed in triplicate. WD-XRF measures up to a depth of a hundred micron to a few millimetres for $\mathrm{Cl}$ and $\mathrm{Br}$, respectively [19]. Taking into consideration that the top-layer thickness of BW30 is around $200 \mathrm{~nm}$ [20], WD-XRF probes the halogen concentrations of the whole membrane, top and support layer included.

\subsubsection{XPS}

Spectra were recorded on a Kratos Axis Supra X-ray Photoelectron Spectrometer employing a monochromated Al $\mathrm{K} \alpha(\mathrm{h} v=1486.7 \mathrm{eV}, 10 \mathrm{~mA}$ emission) X-ray source, hybrid (magnetic/electrostatic) optics with a slot aperture, hemispherical analyser, multichannel plate and delay line detector (DLD) with a take-off angle of $90^{\circ}$. The analyser was operated in fixed analyser transmission (FAT) mode with survey scans taken with a pass energy of $160 \mathrm{eV}$ and high resolution scans with a pass energy of $20 \mathrm{eV}$. All scans were acquired under charge neutralization conditions using a low energy electron gun within the field of the magnetic lens. The resulting spectra were processed using CasaXPS software. Binding energy was referenced to aliphatic carbon at $285.0 \mathrm{eV}$. High resolution spectra were fitted using the " $\mathrm{LF}(\alpha, \beta, \mathrm{w}, \mathrm{m})$ " lineshape corresponding to a numerical convolution of Lorentzian functions (with exponents $\alpha$ and $\beta$ for the high binding energy and low binding energy sides) with a Gaussian (width $\mathrm{m}$ ) and inclusion of tail-damping (w) to provide finite integration limits. Details of this lineshape function are available in the CasaXPS documentation online [21]. These measurements were executed at KU Leuven Campus Kortrijk (Belgium).

Relative sensitivity factors based on Scofield cross-sections were used for quantification. Escape depth correction was performed according to the approximation of electron attenuation length by Seah [22]. The instrument intensity energy response function (IERF) was determined by calibration using gold, silver and copper standards and the NPL calibration software (National Physical Laboratory, UK) [23]. Use of these relative sensitivity factors does not account for any attenuation due to overlayers or other surface contamination and assumes a uniform depth distribution of elements within the information depth of the sample. Matrix 
effects are also discounted [24,25]. Doublets due to non-zero orbital angular momentum were modelled using a fixed ratio of component peaks corresponding with the degeneracy of the total angular momentum states for that set of orbitals. XPS probes the upper $\sim 8 \mathrm{~nm}$ of the top-layer.

\subsubsection{ATR-FTIR}

A FT-IR spectrometer Nicolet iZ10 (Thermo Scientific, Madrid, Spain) with an ultra-highperformance attenuated total reflectance (ATR) plate of germanium crystal (Smart iTR, Thermo Scientific, Madrid, Spain) was used to evaluate the influence of chlorine on the characteristic chemical bonds in the PA top-layer. Spectra were collected from 1400 to $3800 \mathrm{~cm}^{-1}$ with a resolution of $4 \mathrm{~cm}^{-1}$. The spectrometer was controlled using OMNICTM control software (Version 7.0, Thermo Scientific, Madrid, Spain) and the spectrum of each sample was obtained by taking the average of 100 scans to improve the signal-noise ratio. Possible damage of the polymer by irradiation is expected to be minimal, amongst others because of the low energy of IR-waves and because of the short measurement time $(<2 \mathrm{~min})$. Experiments with 32 scans were however repeated to experimentally prove this and indeed, similar spectra as those generated by 100 scans were obtained. In total, three replicates of each sample were taken. These measurements were executed at DW\&PS (Tarragona, Spain).

\subsubsection{SEM}

The morphologies of the top-layers were analyzed at KU Leuven (Belgium) by scanning electron microscopy (SEM) using a Philips XL30 FEG instrument. The samples were sputter coated with $5 \mathrm{~nm}$ of $\mathrm{Pt}$ before the analysis. At least 3 images were taken of each sample.

\subsubsection{AFM}

The surface topography and roughness of the obtained membranes were investigated at KU Leuven (Belgium) using a Dimension 3100D scanning probe microscope (from Bruker) operating in a soft tapping mode under ambient conditions (relative humidity $230 \%$ ). Commercial force probes-cantilevers (PPP-NCSTR probes from NanoAndMore GmbH) made of Si with a nominal spring constant of $7 \mathrm{~N} / \mathrm{m}$ and with the typical tip radius of less than $7 \mathrm{~nm}$ were used for the measurements.

AFM images were flattened with order 1 after scanning. This implies that a least-squares linear fit is made to the data in the scanned region; the resulting best fit is then subtracted from the image. Flattening was done to remove slope from an image. After flattening, the RMS roughness (root-mean-squared roughness) was calculated using WSxM software [26]. The RMS roughness $\mathrm{R}_{\mathrm{rms}}$ is given by the standard deviation of the data,

$$
R_{\mathrm{rms}}=\sqrt{\frac{\sum_{n=1}^{N}\left(z_{n}-\bar{z}\right)^{2}}{N-1}},
$$

where $\bar{z}$ is the average of the $\mathrm{z}$ values within the given area, $\mathrm{z}_{\mathrm{n}}$ is the current $\mathrm{z}$ value, and $\mathrm{N}$ is the number of data points within the given area.

\subsubsection{Zeta potential}

Membrane zeta potential was determined from streaming current measurements with a SurPASS electrokinetic analyzer (Anton Paar). Streaming current was preferred to streaming potential because this latter is likely to be impacted by the membrane body conductance when measurements are performed along the membrane surface (tangential mode) [27]. For each measurement, two identical membrane coupons $(20 \mathrm{~mm}$ x $20 \mathrm{~mm})$ were placed in the adjustable-gap cell from Anton Paar and separated by a distance of $95 \pm 5 \mu \mathrm{m}$. Measurements 
were performed for $\mathrm{pH}$ ranging from c.a. 9 to 2.5 using the automatic titration unit associated with the SurPASS instrument and applying pressure ramps from 0 to 300 mbar. All measurements were performed at room temperature $\left(22 \pm 1^{\circ} \mathrm{C}\right)$ under an inert atmosphere $(\mathrm{N} 2)$ according to the experimental protocol described by Mouhoumed et al. [28]. Streaming current data were analyzed and converted into zeta potentials by means of the Visiolab software. These measurements were executed at Université de Rennes (France).

\subsubsection{PALS}

Positron annihilation lifetime spectroscopy (PALS) is a well-established technique to measure the free volume in polymer membranes. After implantation, the positron thermalizes rapidly and can form a hydrogen-like bound state with an electron, the so-called positronium (Ps). It occurs either as para-positronium (p-Ps) in a spin-singlet state or as ortho-positronium (o-Ps) in a spin-triplet state. The positron of the o-Ps interacts with an electron of its surroundings and annihilates into two gamma-quanta with an average lifetime, the pick-off lifetime, which can be measured and directly correlated to the free volume hole size according to the Tao-Eldrup model [29,30]. This model, assuming spherical holes with infinite potential walls, gives a quantum mechanical description of the correlation of free volume radius and o-Ps lifetime:

$$
\tau_{3}=1 / 2\left[1-\frac{R}{R+\Delta R}+\frac{1}{2 \pi} \sin \left(\frac{2 \pi R}{R+\Delta R}\right)\right] n s
$$

In this equation $\tau_{3}$ is the o-Ps kick-off lifetime, $R$ the radius of the free volume hole and $\Delta R$ the thickness of the electron layer surrounding the free volume hole, which is assumed to be 0.166 $\mathrm{nm}$. This model is valid for lifetimes up to $10 \mathrm{~ns}$. It is however easily extended to longer lifetimes and thus to larger free-volume element sizes [31]. The intensity of the o-Ps is a product of Ps formation probability and the concentration of free volume holes. Therefore, it can be used in some cases to estimate relative changes in the hole concentration.

To measure thin polymer films, an adjustable monoenergetic positron beam is needed, leading to defined implantation profiles [32], even in multi-layered structures [33]. The pulsed low energy positron beam system (PLEPS), which is operated at the neutron induced positron source Munich (NEPOMUC) [34,35], allows such measurements [36,37] and was used for this study.

The monoenergetic positrons are accelerated onto the sample and lose their kinetic energy due to collisions and ionization processes in the first picoseconds after reaching the surface. The length scales of these curves depend on the density of the material and the implantation energy of the positrons. The resulting implantation profiles in polymers can be calculated according to a well-established procedure [32]. For low energies in the keV-range, the mean implantation depth is given by:

$$
z_{\text {mean }}=29.9 \cdot \frac{E^{1.71}}{\rho}
$$

where $E$ depicts the implantation energy and $\rho$ the density.

In this work, PLEPS measurements with implantation energies from 0.5 to $1.5 \mathrm{keV}$ were used. Each membrane was measured at 3 different spots, to account for intra-sample variations. For these spectra, 4 million counts were collected with a count rate of about $10000 \mathrm{cts} / \mathrm{s}$ and a time resolution of about 250 ps. All spectra were evaluated with LT9.2 [38] and POSWIN. The resolution function was determined by measuring $\mathrm{p}$-doped $\mathrm{SiC}$, a sample with known lifetimes. 
The spectra were deconvoluted into four lifetime components ( $\mathrm{p}-\mathrm{Ps}$, free $\mathrm{e}+$ and two o-Ps) leading to overall fit variances from 1.0 to 1.1 .

\section{Results and Discussion}

\subsection{ATR-FTIR}

The ATR-FTIR spectra of the bleached membranes are shown in Figure 4. A thorough analysis of changes in FT-IR peaks due to chlorination was done by Antony et al. and was, amongst others, used as base for the interpretation of the obtained spectra [39]. The characteristic aromatic PA peaks (at 1664, 1609, 1542 and $1450 \mathrm{~cm}^{-1}$ ) remain unchanged for the reference (0 ppm), the passively (i.e. under atmospheric pressure, without permeating) and the actively (i.e. while permeating under 10 bar) chlorinated membranes with $1 \mathrm{ppm} \mathrm{NaOCl}$. Hence, the latter did not suffer from significant hypochlorous acid attack. At higher $\mathrm{NaOCl}$ concentrations $(20$ and $50 \mathrm{ppm})$, the amide II $\left(1542 \mathrm{~cm}^{-1}\right)$ band, corresponding to N-H in-plane bending, shifted to lower wavenumbers, broadened and decreased in intensity significantly. This is an indication of the conversion of amide and amine $\mathrm{N}-\mathrm{H}$ groups into $\mathrm{N}-\mathrm{Cl}$ groups $[39,40]$. The amide I band $\left(1664 \mathrm{~cm}^{-1}\right)$, representing $\mathrm{C}=\mathrm{O}$ stretching, shifted to higher wavenumbers, without substantial changes in band intensity. These frequency-shifts were also observed in lab-scale experiments and explained by the breakage of hydrogen bonds between $\mathrm{C}=\mathrm{O}$ and $\mathrm{N}-\mathrm{H}$ groups after chlorination [39-42]. The intensity of the $1609 \mathrm{~cm}^{-1}$ peak, attributed to $\mathrm{C}=\mathrm{C}$ ring stretching [43] and/or to N-H deformation vibration of the aromatic amide [18], also strongly decreased. This confirms the breakage of hydrogen bonds between polymer chains $[44,45]$, but is also an indication for the occurrence of ring-chlorination [46]. These results suggest that $\mathrm{N}$-chlorination and ring-chlorination via Orton rearrangement [47] occurred for the membranes chlorinated at 20 and 50 ppm NaOCl under acidic conditions, in agreement with Powell et al. [47].

Additionally, when investigating the coating layer (3330 and $2920 \mathrm{~cm}^{-1}$ [20]), a decrease in peak intensity is visible with increasing chlorine concentration. This suggests that the coating layer is (partially) degraded after exposure to chlorine. The same result was obtained in a longterm desalination study where bromination instead of chlorination was observed [6]. However, the broader peak around $3300 \mathrm{~cm}^{-1}$ can also be assigned to amide $\mathrm{N}-\mathrm{H}$ [48], again substantiating that N-chlorination occurred. 

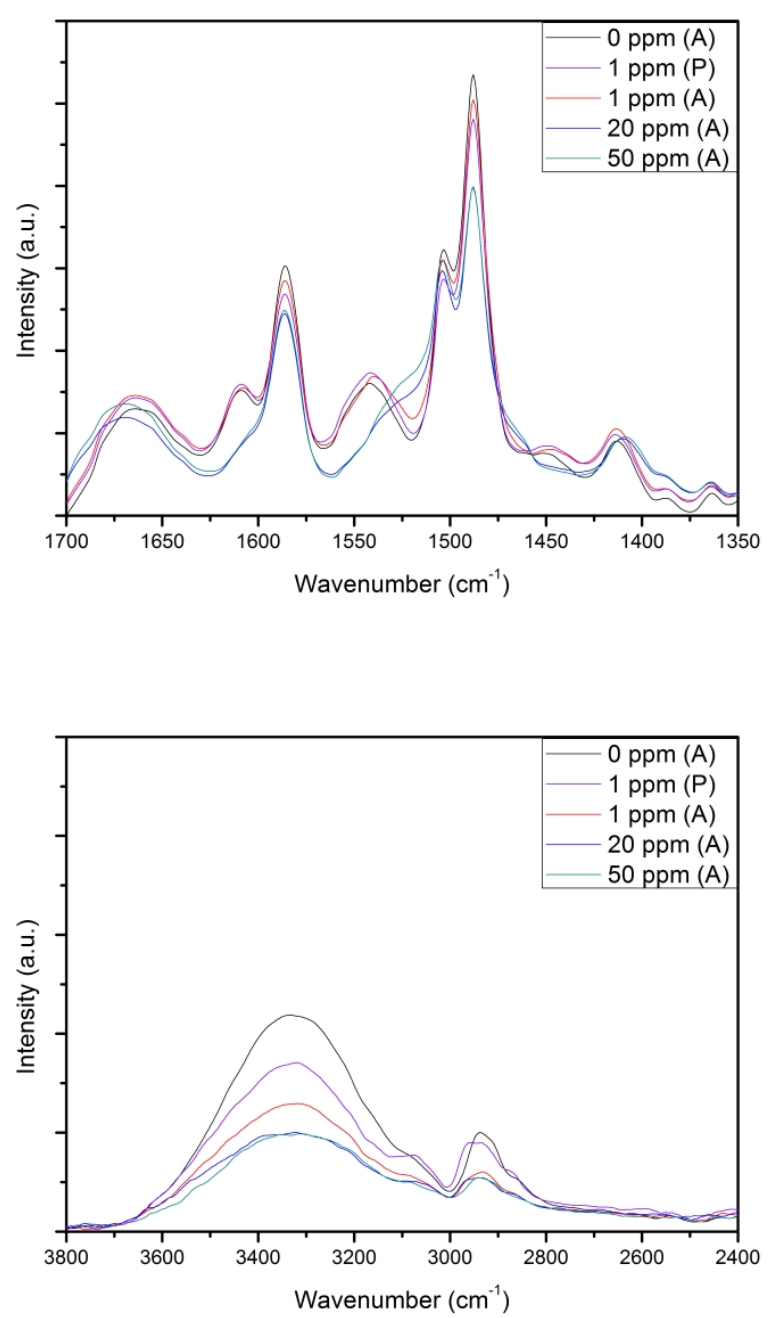

Figure 4: Representative ATR-FTIR spectra for the reference membrane $(0 \mathrm{ppm})$ and chlorinated membranes at $\mathrm{pH} 4$, during 2 h, at 1, 20 and 50 ppm NaOCl. (top) Emphasis on characteristic PA peaks. (bottom) Emphasis on characteristic removable coating layer peaks. $(\mathrm{A})$ and $(\mathrm{P})$ denote active and passive chlorination, respectively.

\subsection{Surface chlorine analysis via WD-XRF and XPS}

WD-XRF and XPS analyses were executed in order to determine the presence of chlorine on the membrane surface and the membrane elemental composition. WD-XRF probes the complete membrane (top and support layer) and the obtained results in this study should be interpreted relative to each other, i.e. they are not absolute. This is due to the lack of a standard series in which the concentration of $\mathrm{Cl}$ on the membrane is exactly known. WD-XRF results show that the surface chlorine content $(\mathrm{in} \% \mathrm{Cl})$ is positively correlated with the active $\mathrm{NaOCl}$ concentration in the feed, suggesting that more $\mathrm{Cl}$ is incorporated in the membrane with increasing $\mathrm{NaOCl}$ dose (Figure 5). 


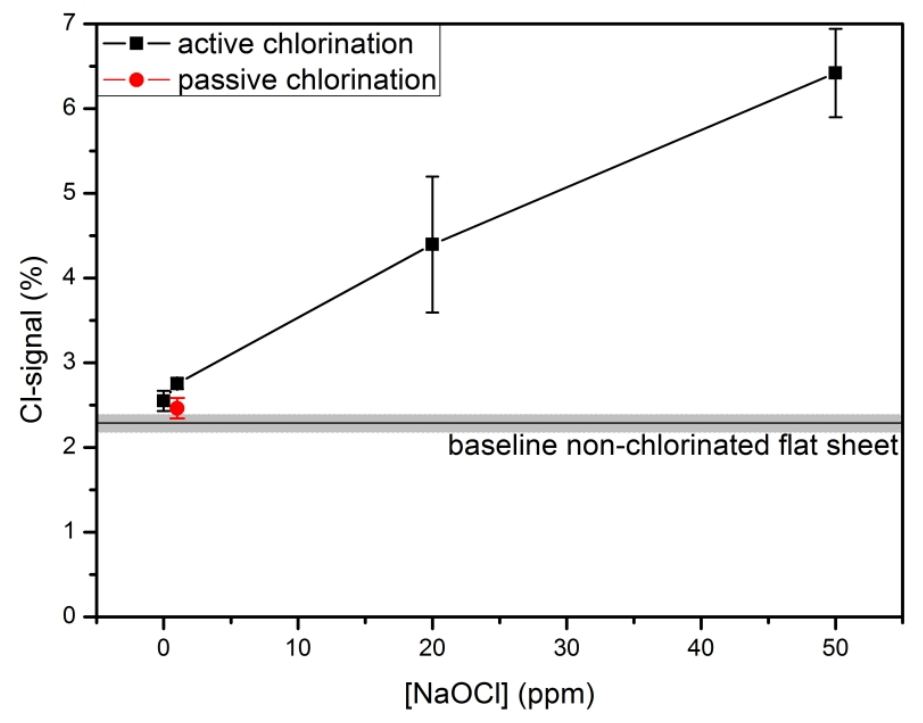

Figure 5: WD-XRF signal of chlorine as a function of the $\mathrm{NaOCl}$ concentration in the feed. Values are the average of 3 replicates. The influence of pressure is depicted through active (10 bar) and passive (immersion) chlorination. A nonchlorinated flat-sheet sample is taken as baseline and the standard deviation of 8 replicates of this membrane is shown in grey.

The results obtained via XPS can be interpreted quantitatively by measuring the peak areas and correcting for the appropriate instrumental factors [49]. The upper $\sim 8 \mathrm{~nm}$ of the membranes contains $\mathrm{O}, \mathrm{N}, \mathrm{C}$ and $\mathrm{Cl}$, and trace amounts of $\mathrm{Na}, \mathrm{Ca}$ and $\mathrm{Si}$ (Table 1). The latter are due to contamination of the sample and the sample preparation. The high standard deviations are indicative of the heterogeneous nature of the surface. However, when plotting the organochlorine $(\mathrm{C}-\mathrm{Cl})$ content as function of $\mathrm{NaOCl}$ concentration in the feed, the same trend is observed as with WD-XRF (Figure 6). In the reference sample, chlorine was only present as chloride $\left(\mathrm{Cl}^{-}\right)$while all other actively chlorinated membranes contained both chloride and covalently bound $\mathrm{C}-\mathrm{Cl}$, as indicated by high resolution spectra of $\mathrm{Cl} 2 \mathrm{p}$ (Figure S1) and in Table 2. The chloride concentration in the membranes treated with $0,20 \mathrm{ppm}$ and $50 \mathrm{ppm}$ $\mathrm{NaOCl}$ was never higher than the sum of the sodium and two times the calcium concentration, suggesting that the chloride was probably present as sodium or calcium chloride contaminations. The low level of chloride in the membrane that was actively chlorinated with $1 \mathrm{ppm}$ could be associated with photochemical decomposition of the chloramide $(\mathrm{N}-\mathrm{Cl})$ species [50], as no contaminating metal cations were detected in this sample. Additionally, it was not possible to deconvolute the Cl-peaks into an additional binding partner, i.e. covalently bound $\mathrm{Cl}$ to $\mathrm{N}$, even though this bond is expected to be present (ATR-FTIR results and the assumption of $\mathrm{N}$-chlorination). This is probably due to the instability of $\mathrm{N}-\mathrm{Cl}$ bonds when bombarded with energetic X-rays. However, the increasing $\mathrm{Cl} / \mathrm{N}$ ratio with increasing $\mathrm{NaOCl}$ concentration in the feed indicates a higher degree of chlorine incorporation in the PA top-layer (Table 2). 
Table 1: Elemental compositions of each sample, averaged over 4 measurements. (A) and (P) denote active and passive chlorination, respectively.

\begin{tabular}{lccccccc}
\hline \multirow{2}{*}{ Sample } & \multicolumn{7}{c}{ Elemental composition (at\%) } \\
\cline { 2 - 8 } & Na 1s & O 1s & N 1s & Ca 2p & C 1s & CI 2p & Si 2p \\
\hline 0 ppm (A) & $0.26 \pm 0.13$ & $22.93 \pm 5.40$ & $2.53 \pm 0.91$ & $0.04 \pm 0.08$ & $73.78 \pm 5.06$ & $0.12 \pm 0.14$ & $0.26 \pm 0.13$ \\
1 ppm (P) & n.d. & $24.89 \pm 3.32$ & $4.59 \pm 2.08$ & $0.10 \pm 0.07$ & $70.43 \pm 1.23$ & n.d. & n.d. \\
1 ppm (A) & n.d. & $22.16 \pm 2.11$ & $6.73 \pm 0.83$ & n.d. & $70.44 \pm 1.23$ & $0.67 \pm 0.17$ & n.d. \\
20 ppm (A) & n.d. & $23.38 \pm 3.27$ & $4.31 \pm 1.92$ & $0.18 \pm 0.23$ & $69.35 \pm 1.05$ & $2.70 \pm 1.48$ & $0.10 \pm 0.20$ \\
50 ppm (A) & $0.04 \pm 0.05$ & $23.66 \pm 4.20$ & $4.18 \pm 2.62$ & $0.51 \pm 0.55$ & $67.79 \pm 0.97$ & $3.82 \pm 1.21$ & n.d. \\
\hline
\end{tabular}

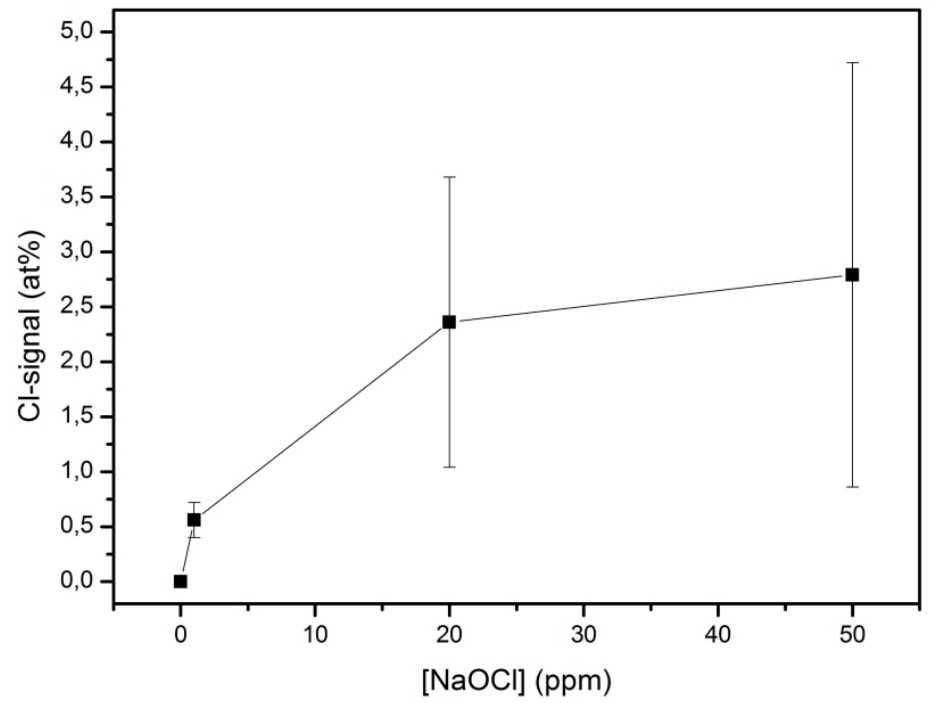

Figure 6: XPS organochlorine (C-Cl) signal as a function of the $\mathrm{NaOCl}$ concentration in the feed, based on 4 measurements. Chlorine in the reference $(0 \mathrm{ppm})$ membrane was only present as chloride $\left(\mathrm{Cl}^{-}\right)$, while all other actively chlorinated membranes contained both $\mathrm{Cl}^{-}$and covalently bound organochlorine. $\mathrm{No} \mathrm{Cl}$ in any form could be detected for the passively chlorinated membrane.

XPS was also used to quantitatively substantiate the degradation of the coating layer, as suggested earlier by ATR FT-IR results. A fully cross-linked MPD/TMC-based PA theoretically contains 75 at $\%$ C, 12.5 at $\% \mathrm{O}$ and 12.5 at $\% \mathrm{~N}$. The total O-content of all analysed BW30 membranes is significantly higher than the theoretical $12.5 \%$, substantiating the presence of the coating layer. However, the O-content did not significantly decrease with increasing chlorine concentration in the feed (Table 1). Via high resolution scans, it was possible to associate peaks to the removable coating layer as well as to the PA top-layer (Figure S2) but no significant changes in coating to PA-ratios between the different samples were detected. This is probably due to the relatively high standard deviation in surface compositions. Any changes in coating content induced by the chlorination process may thus be more subtle than the inhomogeneity of the membrane surface. 
Table 2: Chloramide $(\mathrm{N}-\mathrm{Cl})$, chloride $\left(\mathrm{Cl}^{-}\right)$, organochlorine $(\mathrm{C}-\mathrm{Cl})$ and cation concentrations, averaged over 4 measurements. $\mathrm{Cl} / \mathrm{N}$ ratio is also shown, based on amide $\mathrm{N}$ and $\mathrm{C}-\mathrm{Cl}$, averaged over 4 measurements.

\begin{tabular}{|c|c|c|c|c|c|c|}
\hline \multirow[t]{2}{*}{ Sample } & \multicolumn{6}{|c|}{ Elemental composition (at \%) } \\
\hline & Amide N 1s & C-Cl 2p & $\mathrm{Cl}^{-} 2 \mathrm{p}$ & $\mathrm{Cl} / \mathrm{N}$ & Na 1s & Ca 2p \\
\hline 0 ppm (A) & $2.53 \pm 0.91$ & n.d. & $0.12 \pm 0.14$ & - & $0.26 \pm 0.13$ & $0.04 \pm 0.08$ \\
\hline $1 \mathrm{ppm}(\mathrm{P})$ & $4.59 \pm 2.08$ & n.d. & n.d. & - & n.d. & $0.10 \pm 0.07$ \\
\hline 1 ppm (A) & $6.73 \pm 0.83$ & $0.56 \pm 0.16$ & $0.11 \pm 0.02$ & $0.08 \pm 0.02$ & n.d. & n.d. \\
\hline 20 ppm (A) & $4.31 \pm 1.92$ & $2.36 \pm 1.32$ & $0.34 \pm 0.29$ & $0.52 \pm 0.08$ & n.d. & $0.18 \pm 0.23$ \\
\hline $50 \mathrm{ppm}(\mathrm{A})$ & $4.18 \pm 2.62$ & $2.79 \pm 1.93$ & $1.02 \pm 0.94$ & $0.61 \pm 0.16$ & $0.04 \pm 0.05$ & $0.51 \pm 0.55$ \\
\hline
\end{tabular}

To investigate the influence of pressure on chlorine incorporation, one element was chlorinated under passive conditions (i.e. via simple immersion, without applying pressure) and compared to an actively chlorinated element (i.e. under 10 bar), both with $1 \mathrm{ppm} \mathrm{NaOCl}$ in the feed. No $\mathrm{Cl}$ was detected in any form (i.e. $\mathrm{C}-\mathrm{Cl}, \mathrm{Cl}^{-}$) for the passively chlorinated membrane, while a total Cl-content of $0.56 \pm 0.16$ at $\%$ for the actively chlorinated membrane was observed (Table 2). These results suggest, just like those obtained via WD-XRF, that the application of pressure results in a higher degree of $\mathrm{Cl}$-incorporation compared to chlorination via immersion. The same conclusion can be deducted by comparing the obtained results in this study (active mode) with lab-scale experiments of Kwon et al.[40]. They observed a surface chlorine content of around 2.5 at\% (via XPS) after a chlorination step (2000 ppm NaOCl) via immersion for $1 \mathrm{~h}$ at pH4. Here, at much less severe ageing conditions (i.e. $20 \mathrm{ppm} \mathrm{NaOCl}, 2.5 \mathrm{~h}$ ) but under the application of pressure, the same amount of chlorine is present in the upper part of the selective layer $( \pm 2.70 \mathrm{at} \%)$. The findings of this study thus suggest that the application of pressure is an important parameter that should be considered during future chlorination studies.

\subsection{Surface topography study using SEM and AFM}

The surface topography of the chlorinated membranes was analysed with AFM and SEM. BW30 membranes contain, on top of the aromatic PA selective layer, a removable coating layer [18], which is believed to preferentially settle in the valleys of the typical peak-and valleystructures [51]. As a consequence, this would render the rough structure less pronounced. Based on the SEM images (Figure 7), the reference membrane indeed appears to be slightly smoother, while the chlorinated membranes do contain the familiar protuberances of the rough ridge-andvalley structure [52]. This is another indication, next to ATR-FTIR results, that the coating layer is partially removed from the membrane, as reported in immersion (passive) lab-scale experiments, but at much higher chlorine doses [8]. These results thus suggest that active chlorination has a more severe impact on the membrane compared to passive chlorination. However, when comparing the SEM image of active chlorination with that of passive chlorination, it is difficult to assess the exact degree of coating coverage, hence making it perilous to state which operation mode exacerbates the oxidation reactions. Additionally, one should take into account that very low $\mathrm{NaOCl}$ concentrations were used (i.e. $1 \mathrm{ppm}$ ), probably not allowing to see a significant change in top-layer morphology. 

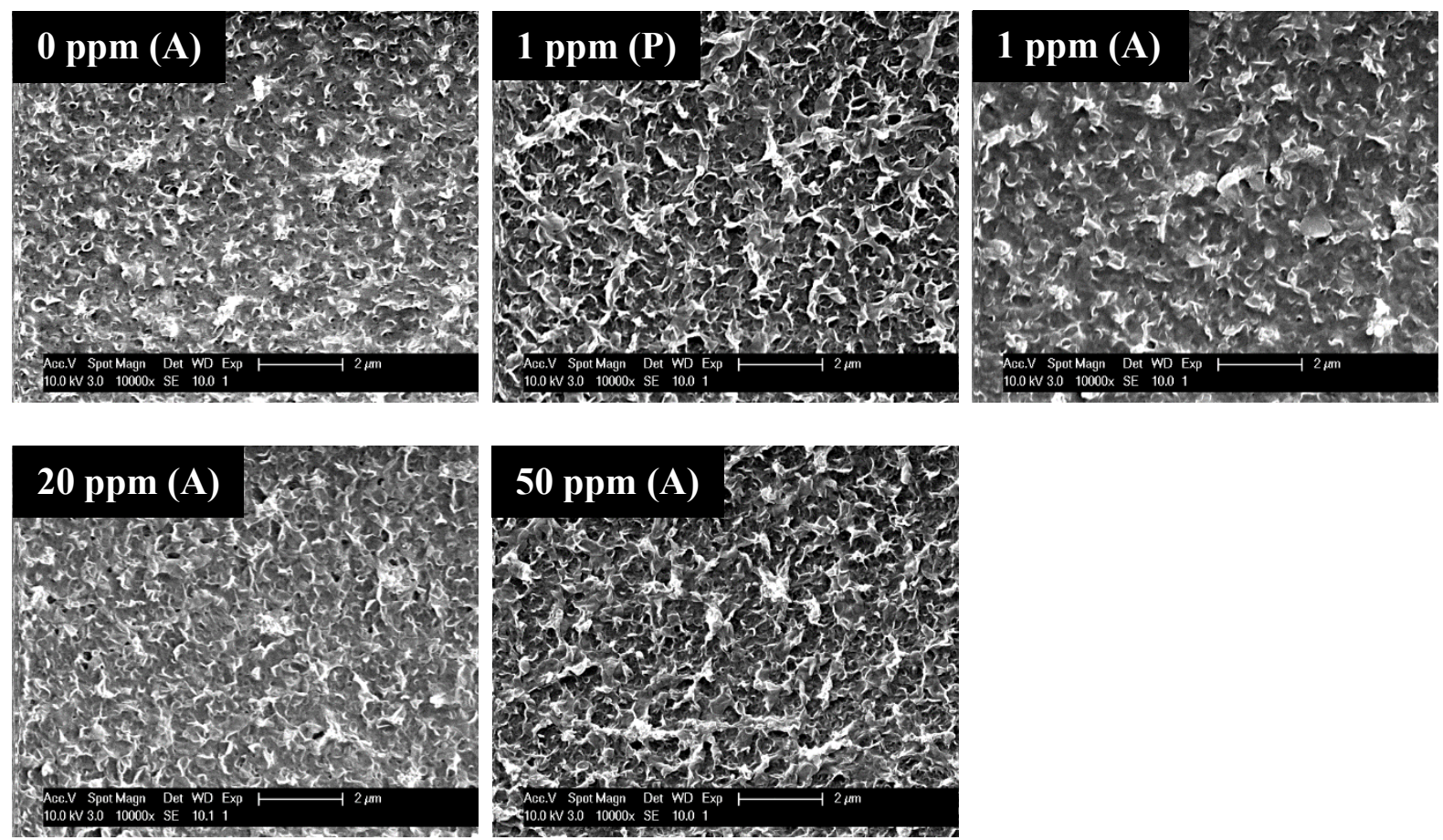

Figure 7: Representative SEM images of the surface of chlorinated membranes from the BW30 elements. (A) and (P) denote active and passive chlorination, respectively.
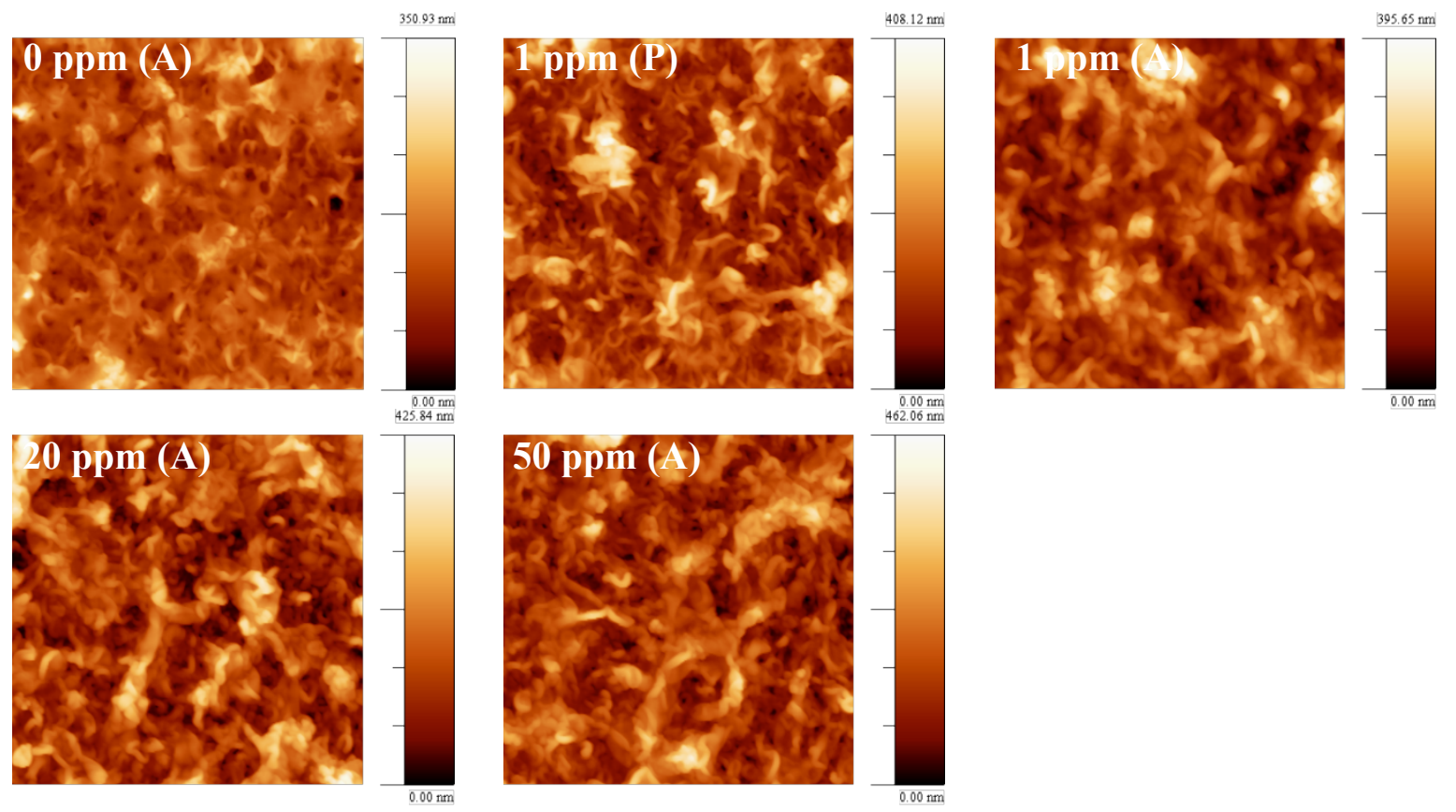

Figure 8: Representative AFM images of the surface of chlorinated membranes from the BW30 elements. Each AFM image represents an area of $5 \times 5 \mathrm{~m}^{2}$ and the z-amplitude shown in $\mathrm{nm}$. (A) and (P) denote active and passive chlorination, respectively.

AFM measurements confirmed quantitatively the higher roughness of the chlorinated membranes compared to the reference one (Figure 8 and Figure 9). The reference BW30 membrane has an average RMS roughness ( $\mathrm{R}_{\mathrm{RMS}}$ ) of $45.36 \mathrm{~nm}$. The presence of chlorine in the feed water caused the $\mathrm{R}_{\mathrm{RMS}}$ to increase over the whole concentration range. At the highest chlorine concentration, this value increased up to $65.93 \mathrm{~nm}$, being significantly higher than for the reference membrane. No significant difference in $\mathrm{R}_{\mathrm{RMS}}$ was observed between active and passive chlorination, partially due to the relatively high inhomogeneity of the sample. However, 
both membranes are rougher than the non-chlorinated one. The increase in roughness was both substantiated and contradicted for similar membrane chemistries by others $[9,12]$. Buch et al. argued that the decrease of intra- and inter-chain H-bonding can lead to higher rotational freedom of the polymer chains, thus facilitating reorganisation of the chains to form a rougher surface [53]. Even though a decrease in H-bonding was confirmed by ATR-FTIR, the more pronounced ridge-and-valley structure can, in this study, also be related to disappearance or degradation of the coating layer.

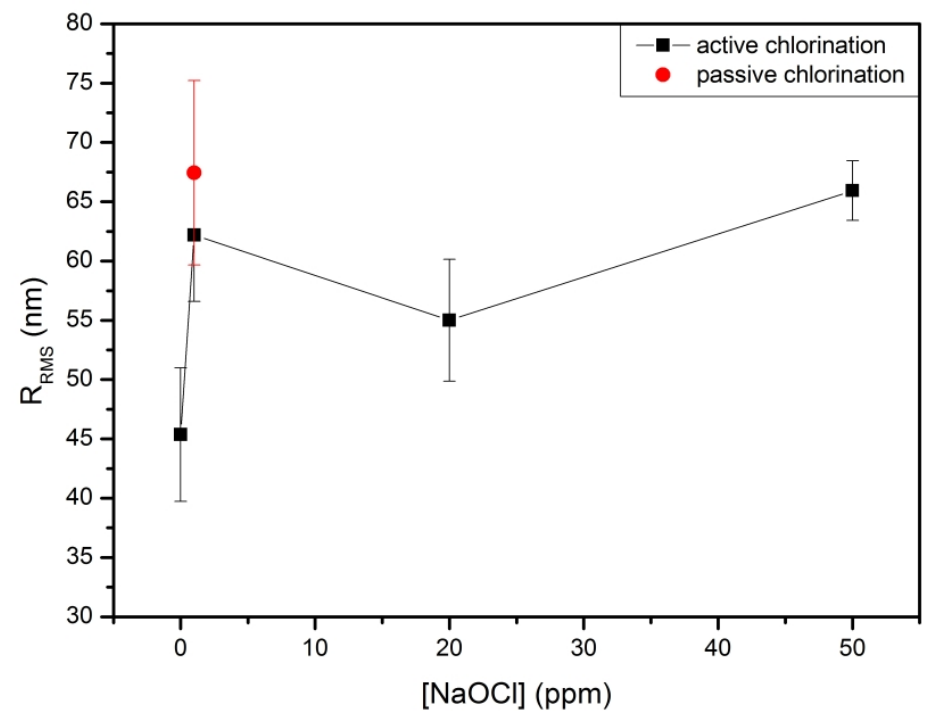

Figure 9: The root-mean-square roughness $\left(\mathrm{R}_{\mathrm{RMS}}\right)$ of the actively and passively chlorinated membranes as function of $\mathrm{NaOCl}$ concentration in the feed. Values shown are the average of at least 3 replicates, each of which was obtained by scanning a $5 \times 5 \mathrm{~m}^{2}$ surface area.

\subsection{Surface charge: zeta-potential measurements}

The effect of hypochlorous acid ageing on membrane surface charge density was investigated via zeta-potential measurements. Surprisingly, no significant differences in the zeta-potential curve and in the iso-electric point (IEP) between the reference and the chlorinated membranes are observed (Figure 10). Typically, a zeta potential curve shifts to lower values over the whole $\mathrm{pH}$ range after chlorination, as does the membrane's IEP [8,14]. At low $\mathrm{pH}$, this can tentatively be explained by the amidic $\mathrm{N}$ which can no longer be protonated due to the conversion in $\mathrm{N}-\mathrm{Cl}$ groups, while at high $\mathrm{pH}$, an increase in carboxylic acids groups appears due to chain cleavage after chlorination. Nevertheless, here, it is believed that the chlorine concentrations and/or exposure time are too low to induce significant changes in the membrane surface charge density, even though ATR FT-IR measurements did prove alterations in the chemical functional groups. 


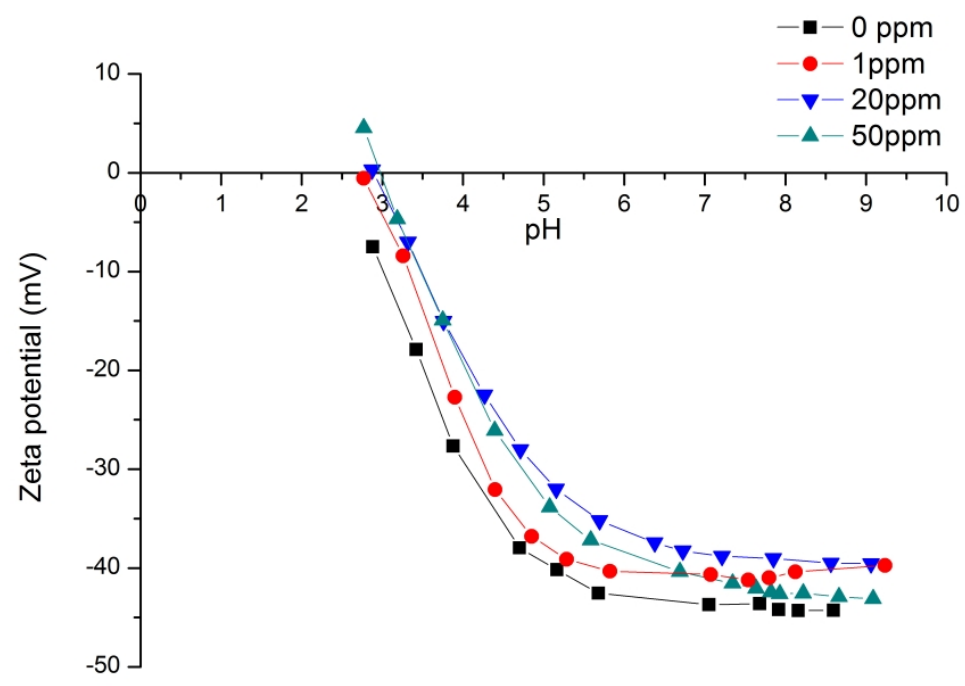

Figure 10: Zeta-potential of the actively chlorinated membranes as function of $\mathrm{NaOCl}$ concentration in the feed.

\subsection{Membrane performance at real-scale}

\subsubsection{Active chlorination}

The membrane water permeability coefficient $\mathrm{A}\left(\mathrm{L} \mathrm{m}^{-2} \mathrm{~h}^{-1} \mathrm{bar}^{-1}\right)$ of the actively chlorinated membranes at $\mathrm{pH} 4$ proportionally decreased over the whole concentration range (Figure 11). A negative $\Delta \mathrm{A}$ signifies a lower water permeability coefficient in the post-Cl-ST than in the pre-Cl-ST and can thus mainly be attributed to the chlorination step. The small decrease in A for the non-chlorinated reference membrane is probably due to statistical fluctuations. The same holds true for the $1 \mathrm{ppm}$-membrane, suggesting that a chlorination step of $1 \mathrm{ppm} \mathrm{NaOCl}$ during $2.5 \mathrm{~h}$ does not significantly alter the membrane flux. At higher chlorine concentrations, however, a strong decrease in A is observed: $-31.7 \%$ for $20 \mathrm{ppm}$ and $-42.6 \%$ for $50 \mathrm{ppm}$, suggesting that the selective PA layer becomes denser/tighter with increasing $\mathrm{NaOCl}$ concentration in the feed. However, it is believed that when exceeding a certain threshold concentration of $\mathrm{NaOCl}$, permeate flux and salt passage will both increase, as the PA chains will get hydrolysed. This threshold is however not attained during the applied bleaching conditions in this study. The actual A values of each standard test can be found in Supplementary Material (Figure S3).

The salt passage (SP), based on the difference in total ions between feed and permeate, of the actively chlorinated membranes decreased over the whole concentration series at $\mathrm{pH} 4:-81.5 \%$ for $20 \mathrm{ppm}$ and $-90 \%$ for $50 \mathrm{ppm}$ (Figure 11). The actual SP and rejection values (based on total ions) of each standard test can be found in Figures $\mathbf{S 4}$ and S5, respectively. The rejection of IPA, based on TOC measurements, also significantly increased for all chlorinated membranes, except for the 1 ppm-membrane (Figure S6). The rejection values for boron increased between pre- and post-Cl-ST for all chlorinated membranes (Figure S7). As the toplayer became thus more selective after chlorination for both salt and neutral solutes, it is therefore difficult to draw general conclusions on the prevalence of different rejection mechanisms (size-exclusion for neutral solutes and electrostatic repulsion for charged solutes).

The typical trade-off between rejection and permeability [54] is substantiated by these results. The decline and incline in, respectively, $\mathrm{A}$ and $\mathrm{R}$ may be due to structural changes in the 
polymer, such as pore collapse or the formation of extra cross-links. To investigate whether the free-volume element size was affected by chlorination, PALS experiments were conducted.

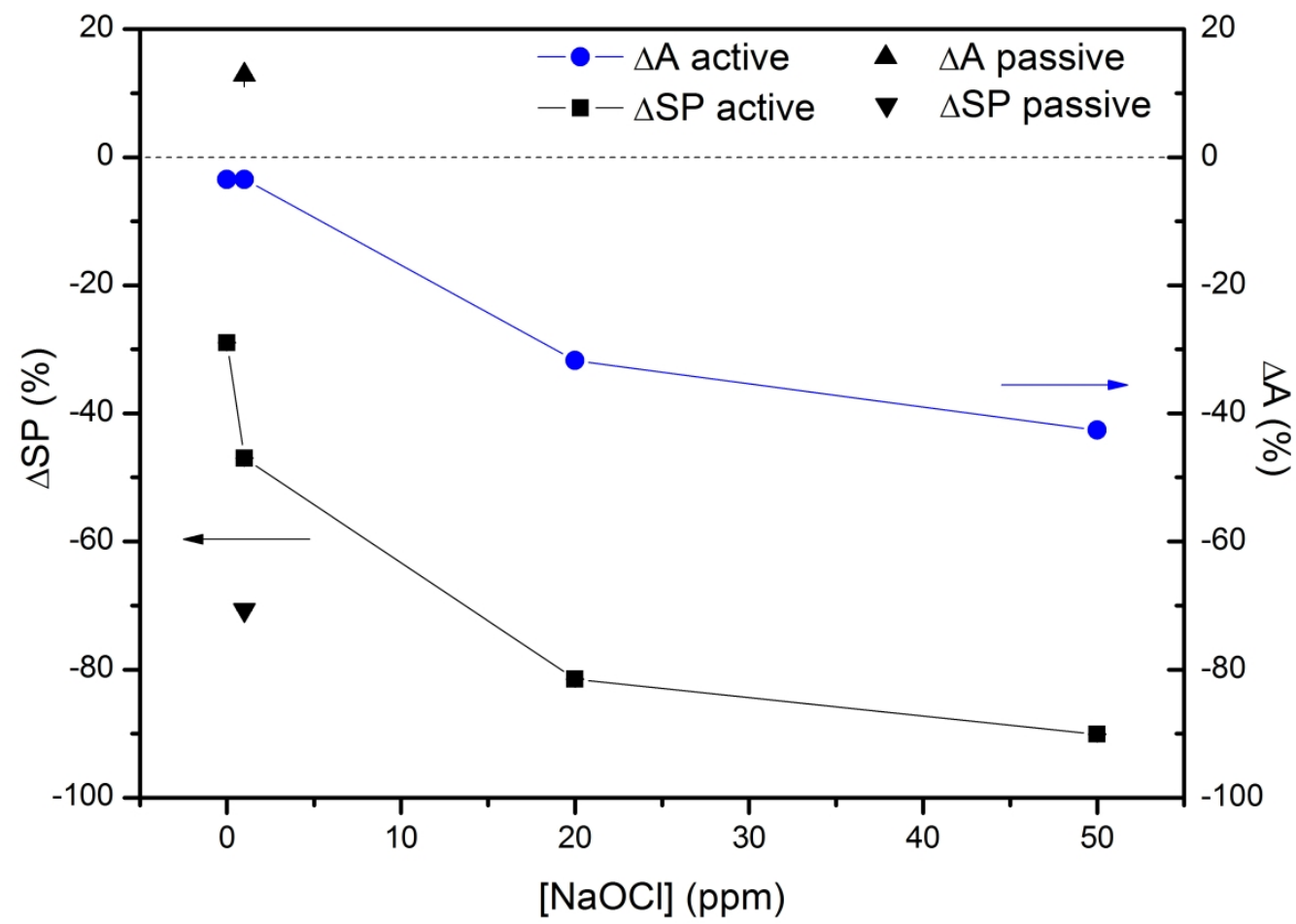

Figure 11: Change in membrane permeability coefficient (A) and salt passage (SP), based on total ions, of BW30 8" membrane elements before and after the chlorination step. Filtration conditions of standard tests: $\mathrm{NaCl}(2000 \mathrm{ppm})$, iso-propanol $(100 \mathrm{ppm})$ and boric acid $(5 \mathrm{ppm})$ in $\mathrm{RO}$ permeate at $15.5 \mathrm{bar}, 25^{\circ} \mathrm{C}, \mathrm{pH8}$ and a recovery of $15 \%$. Values are based on average values of SP and A of pre- and post-Cl-STs.

The filtration results of the actively chlorinated membranes in this study are in agreement with those of the I $^{\text {st }}$ quadrant of Figure 2, in which chlorination was executed at lab-scale via immersion at $\mathrm{pH} 5$. One could hence conclude that results from lab-scale experiments can be transferred to industrial conditions and that pressure does thus not play a significant role. However, several other studies are not in agreement with Do et al. [14] (Figure 2), as they observed a decrease in both rejection and permeability after contact with $\mathrm{NaOCl}$ at $\mathrm{pH} 4[9,55]$. Others even reported an increase in A-value with a decrease in $\mathrm{R}$ under similar conditions [56]. These inconsistencies make it troublesome to draw strong conclusions on whether the application of pressure exacerbates the chlorination process or not. Nevertheless, the characterization results obtained in this study have already confirmed that pressure does affect the degree of chlorine incorporation and membrane morphology. In order to further supplement these observations, the performance of a passively chlorinated membrane is compared to that of a membrane that was treated actively.

\subsubsection{Passive chlorination}

A substantial influence of the application of pressure during the ageing step on membrane performance is certainly observed (Figure 11). The application of $1 \mathrm{ppm} \mathrm{NaOCl}$ under pressure caused a decrease in permeate flux of $-3.45 \%$, while it caused an increase of $+12.89 \%$ when the membrane was chlorinated passively. In both cases, SP, based on total ions, decreased: $-47 \%$ and $-71 \%$, for active and passive chlorination, respectively. The actual A, SP and R values of 
the passively chlorinated membrane can be found in, respectively, Figures S3, S4 and S5. Boron rejection increased for both the passively and actively chlorinated membranes (Figure S7). The rejection of TOC increased from $<85 \%$ to $100 \%$ after the passive chlorination step, while it decreased significantly for the actively chlorinated membrane (Figure S6). These observations prove that the final membrane performance after chlorination is notably influenced by applying a certain pressure, as could be anticipated from the changes in membrane morphology and elemental composition (see 3.2. and 3.3.).

It is worth noting that, after a passive chlorination step of $1 \mathrm{ppm}$ for $2.5 \mathrm{~h}$ at $\mathrm{pH} 4$, an increase in permeate flux and rejection of total ions, boron and TOC is observed. Hence, a superior membrane compared to the untreated pristine one is obtained. This effect has been reported in literature, referring to certain chlorine exposure conditions (caustic $\mathrm{pH}$, immersion mode) which are used as post-treatment step to enhance membrane performance [14,44,57]. Here, however, the same result is observed at acidic $\mathrm{pH}$. Furthermore, it is surprising that the realscale results of this study from passive chlorination do not coincide with the $\mathrm{I}^{\text {st }}$ quadrant of Figure 2, while those from active chlorination do. This is again a clear indication that the exact mechanism of chlorine attack on PA-based TFC membranes is still not fully understood and that many parameters influence the final membrane performance.

The results obtained in this real-scale study emphasize once again the importance of the experimental set-up for testing the chlorine resistance of polymeric membranes [4]. Therefore, in order to get a valid understanding of membrane damage due to active chlorination in industry, the authors suggest to conduct further lab-scale chlorination studies in active rather than in passive mode.

\subsection{Free-volume element size determination using PALS}

In literature, two different hypotheses exist to explain why permeate flux decreases after chlorination. One is based on the so-called "tightening effect", in which the membrane becomes more "tight", due to the occurrence of extra cross-linking reactions and the formation of azobonds [58-60]. The other reasons that, due to a decrease in H-bonding degree by the conversion of amidic $\mathrm{N}-\mathrm{H}$ to $\mathrm{N}-\mathrm{Cl}$, the polymer is more flexible and loose and is thus more sensitive to collapse once pressure is applied $[42,44-46,55,61,62]$. However, irrespective the occurring phenomenon, there is, up to now, no quantitative evidence for the decrease of free-volume after chlorination. Therefore, in order to assess whether the PA top-layer became denser after hypochlorous acid ageing, positron annihilation lifetime spectroscopy (PALS) was used. It should be noted that free-volume elements correspond to dynamic sub-nanometer spaces between polymer chains [63], conform the general descript of a "dense" polyamide top-layer.

Figure 12 shows the o-Ps lifetime $\left(\tau_{3}\right)$ and intensity $\left(\mathrm{I}_{3}\right)$ as function of implantation energy, which can be converted into mean implantation depth. o-Ps lifetimes can be related to freevolume element size $[29,30]$, while o-Ps intensity may not directly be related to free-volume concentration as it is also affected by the Ps formation probability [64]. Over the whole energy range, the o-Ps intensity of the reference, non-chlorinated membrane is substantially higher compared to the chlorinated membranes. This may suggest that $\mathrm{Cl}$-atoms in the polymer inhibit Ps formation [65]. However, at higher chlorine concentrations, a counter effect is observed, which causes the intensity to rise again. This phenomenon of anti-inhibition is reported as consequence of the presence of halogenated compounds in polycarbonates and polysulfone matrices [66]. At this moment, there is not enough evidence to chemically explain the combined effect of inhibition at low chlorine concentration and anti-inhibition at higher concentration.

Regarding the o-Ps lifetime, significant differences are observed at different implantation energies (Figure 12). At $0.5 \mathrm{keV}$, surface effects may occur and the observed lifetime can 
therefore not be fully associated to the internal structure of the top-layer [67]. Additionally, due to the highly inhomogeneous ridge-and-valley nature and, more generally, due to changes in the thickness of the PA layer, the porous support may influence the o-Ps lifetime at $2 \mathrm{keV}$. At this energy, the mean implantation depth of the Ps is around $100 \mathrm{~nm}$ and as their energy distribution is expressed as a Makhovian implantation profile, a significant part of the Ps annihilate in the support layer [32]. These generally porous support layers have quite long lifetimes [68] and therefore complicate the evaluation of the o-Ps present in the top-layer. To disclose changes in the internal structure of chlorinated membranes, it is thus most interesting to investigate the o-Ps lifetime and intensity at implantation energies of $1 \mathrm{keV}$.

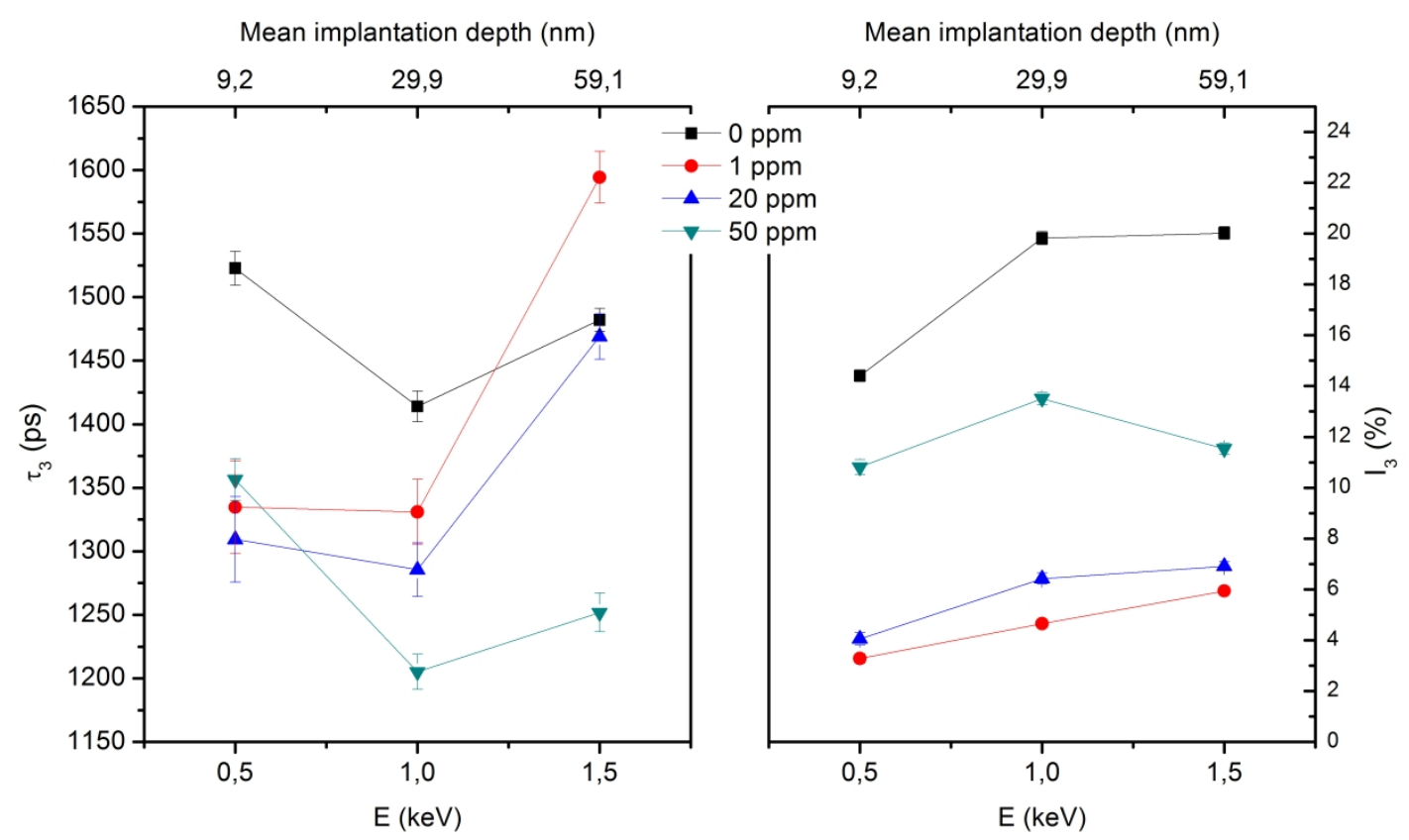

Figure 12: o-Ps lifetime $\left(\tau_{3}\right)$ and intensity $\left(I_{3}\right)$ as function of different positron implantation energies and corresponding implantation depths. Data from one measurement point of all actively chlorinated membranes with $0,1,20$ and $50 \mathrm{ppm}$ $\mathrm{NaOCl}$ in the feed.

At an implantation energy of $1 \mathrm{keV}$ (i.e. mean implantation depth $\sim 30 \mathrm{~nm}$ ), a significant decrease in o-Ps lifetime, and thus in free-volume element size, is observed with increasing chlorine concentration (Figure 13). To account for intra-sample variations, this experiment was repeated at 3 different positions on each membrane sheet. The same trend between o-Ps lifetime and chlorine dose is observed for every position. This observation thus quantitatively substantiates for the first time a decrease in the size of free-volume elements of the PA toplayer due to chlorine exposure under pressure at acidic $\mathrm{pH}$. Additionally, the o-Ps intensity is the highest for the reference, non-chlorinated membrane, and decreases significantly when chlorine is incorporated in the membrane. However, no correlation between chlorine dose and o-Ps intensity is found. 


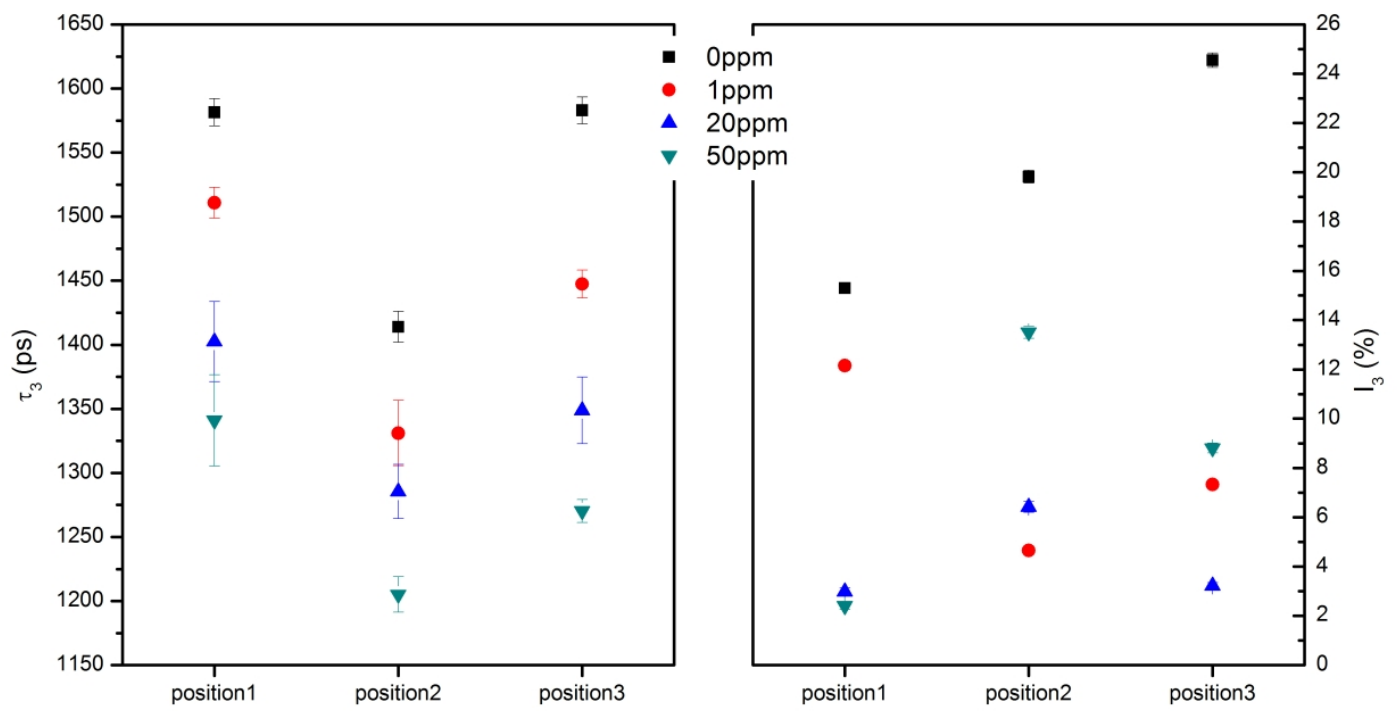

Figure 13: o-Ps lifetime $\left(\tau_{3}\right)$ and intensity $\left(\mathrm{I}_{3}\right)$ at $1 \mathrm{keV}(\sim$ mean implantation depth of $30 \mathrm{~nm})$ as function of different sample positions for all actively chlorinated membranes with $0,1,20$ and $50 \mathrm{ppm} \mathrm{NaOCl}$ in the feed. Values are from one measurement point and 3 different positions of each sample were probed.

The correlation between RO performance and free-volume element size is plotted in Figure 14. The element radius of the pristine reference membrane lies around $2.2 \AA$, which is in agreement with the values reported in literature for RO membranes $[63,69,70]$, and decreased up to roughly $1.95 \AA$ at $50 \mathrm{ppm} \mathrm{NaOCl}$ under active chlorination. Accordingly, solute rejection increased and permeate flux decreased. On the other hand, for the passively chlorinated membrane, the increase in both $\mathrm{A}$ and $\mathrm{R}$ after chlorination is translated into bigger free-volume elements of the PA top-layer. This observation once again confirms that the application of pressure during the chlorination step is a key parameter in the behaviour of PA towards chlorine-induced oxidation. Additionally, these results evidence that the free-volume element radius is an important parameter governing transport through the active membrane layer, as included in the thermodynamic diffusion coefficient of the solution-diffusion model [71].

As mentioned earlier, the decrease in pore size due to chlorination can be explained by the polymer tightening effect or pressure-induced polymer collapse due to disruption of intermolecular hydrogen bonds. At this moment, not enough evidence is available to claim which is the main cause attributed to the decrease in free-volume element size due to chlorination. However, the fact that the passively chlorinated membrane did not suffer from polymer tightening, but rather underwent an enlargement of its free-volume elements, suggests that pore collapse might have occurred for the actively chlorinated membranes, as here $10 \mathrm{bar}$ was applied during the chlorination step. Still, the difference in the amount of organochlorine present in the top-layer (detected via XPS) is believed to also play an important role in the tightening effect. In any case, the results obtained via PALS prove, for the first time in a quantitative way, the decrease in free-volume element size due to hypochlorous acid ageing under pressure. 

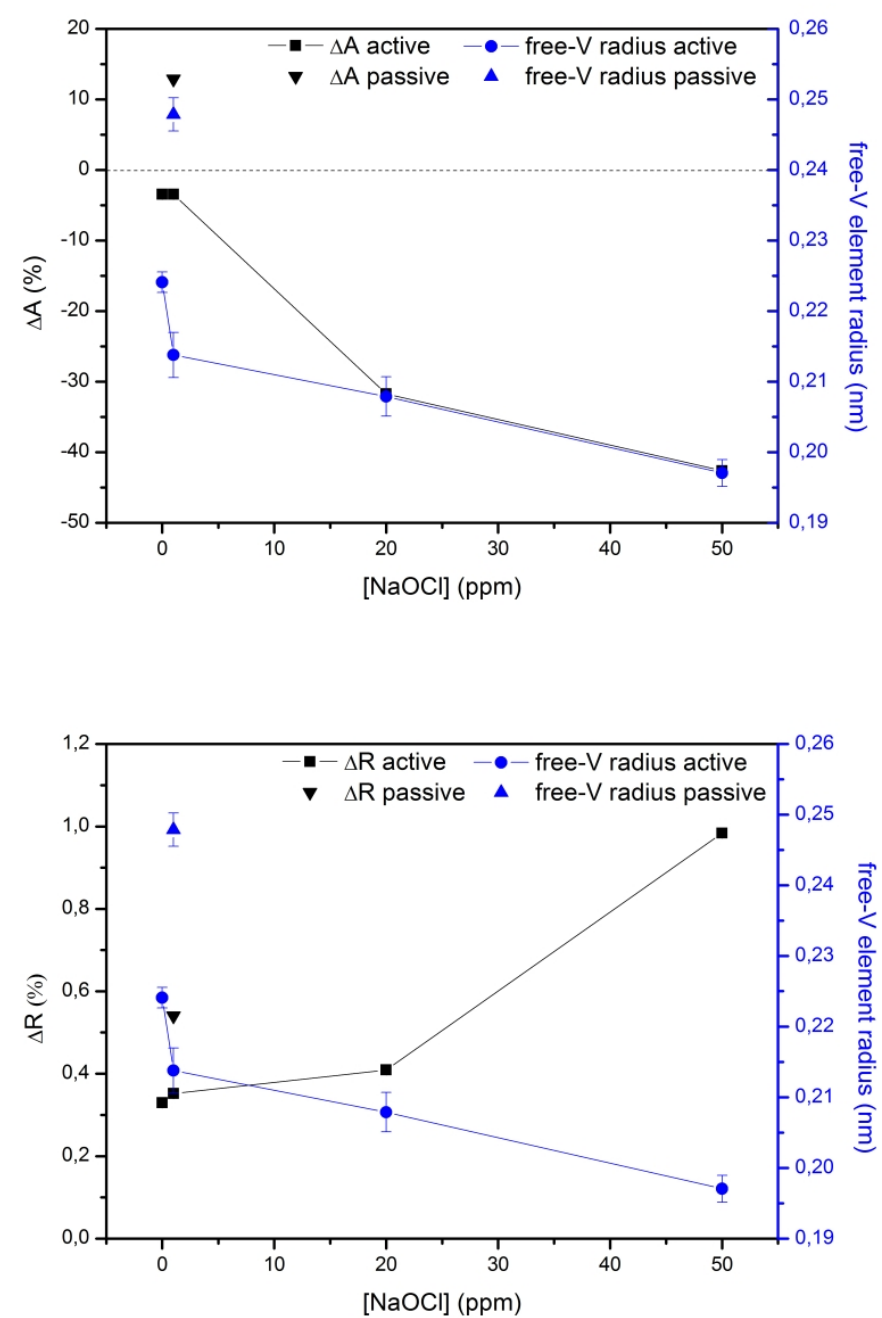

Figure 14: Change in the membrane water permeability coefficient (A) (top) and rejection (R) (bottom) before and after hypochlorite treatment as function of $\mathrm{NaOCl}$ concentration in the feed and related to free-volume hole radius. PALS values are from one representative measurement point.

\section{Conclusions}

A real-scale study was conducted to investigate the effect of chlorine exposure on DOW FILMTEC $^{\mathrm{TM}}$ BW30 membrane elements under industrial conditions. The membranes were actively chlorinated at $10 \mathrm{bar}$, at concentrations of 1,20 and $50 \mathrm{ppm} \mathrm{NaOCl}$, during $2.5 \mathrm{~h}$ at $\mathrm{pH} 4$. With increasing chlorine concentration in the feed, more chlorine was incorporated via Nand ring-chlorination and a lower degree of $\mathrm{H}$-bonding was observed. The surface charge of the membrane did not alter significantly, while the roughness increased and the typical ridge-andvalley structure became more visible. There are indications that the coating on top of the PA layer also degraded partially. Additionally, the membrane rejection increased, the membrane flux decreased and the free-volume hole size, determined via PALS, decreased proportionally with increasing chlorine concentration. The PALS results quantitatively substantiate the socalled polymer tightening effect due to chlorination for the first time. At $50 \mathrm{ppm}$ for example, SP decreased with almost $90 \%$, flux decreased down to $42.6 \%$ of its initial value and freevolume elements decreased in size with $13 \%$. Low chlorine concentrations and relatively short contact times can thus have a very large impact on membrane performance in industry. One membrane was also chlorinated passively at $\mathrm{pH} 4$ (i.e. by recirculating the oxidizing solution at atmospheric pressure, hence without membrane permeation), which resulted in both an increase 
in flux and rejection. Even though no organochlorine (C-Cl) could be detected via XPS, the free-volume elements of the PA top-layer increased in size, as opposed to the actively chlorinated membranes. Thus, the application of pressure during chlorination had a different influence on the membrane performance and morphology and should be considered as an important parameter in the ageing process. To correctly mimic accidental chlorination in water treatment plants, lab-scale studies should hence focus on active rather than on passive chlorination.

\section{Acknowledgements}

The authors are grateful to KU Leuven for support through OT/11/061, as well as the IAP 6/27 on Functional Supramolecular systems of the Belgian Federal Government. R.V. thanks Research Foundation-Flanders (FWO) for a SB-PhD fellowship (1S00917N). Great appreciation is extended to The Dow Chemical Company for providing an internship at Dow Water and Process Solutions in Tarragona, Spain. In particular, G. Navarro, Mireia Font, Natalia Carpi, and Patricia Carmona are gratefully acknowledged for their assistance and for performing the WD-XRF and total-ion measurements. J. Warczok is likewise thanked for her valuable input. A. Volodin, from the laboratory of Solid State Physics from KU Leuven, is acknowledged for the AFM measurements. T. Stassin is kindly acknowledged for recording SEM images. This work is based upon experiments performed at the NEPOMUC PLEPS instrument operated by FRM-II at the Heinz Maier-Leibnitz Zentrum (MLZ), Garching, Germany. W. T. and S. E. thank FWO (G.0C60.13N), KU Leuven (OT/14/072) and the European Union's European Fund for Regional Development, Flanders Innovation \& Entrepreneurship and the Province of West-Flanders (Accelerate3 project, Interreg VlaanderenNederland programme) for financial support. W. T. also thanks the Province of West-Flanders for his Provincial Chair in Advanced Materials. 


\section{Bibliography}

[1] A. Hedberg, R. Pardo, A. Frontini, T. Daryoush, Reaching for blue gold: How the EU can rise to the water challenge while reaping the rewards, 2015.

[2] UNESCO, The United Nations World Water Development Report 2015: Water for a sustainable world, 2015.

[3] J.R. Werber, C.O. Osuji, M. Elimelech, Materials for next-generation desalination and water purification membranes, Nat. Rev. Mater. (2016) 16018. doi:10.1038/natrevmats.2016.18.

[4] R. Verbeke, V. Gómez, I.F.J. Vankelecom, Chlorine-resistance of reverse osmosis (RO) polyamide membranes, Prog. Polym. Sci. 72 (2017) 1-15. doi:10.1016/j.progpolymsci.2017.05.003.

[5] Dow Water \& Process Solutions, FILMTEC ${ }^{\mathrm{TM}}$ Reverse Osmosis Membranes Technical Manual, 2011.

[6] T. Suzuki, R. Tanaka, M. Tahara, Y. Isamu, M. Niinae, L. Lin, J. Wang, J. Luh, O. Coronell, Relationship between performance deterioration of a polyamide reverse osmosis membrane used in a seawater desalination plant and changes in its physicochemical properties, Water Res. 100 (2016) 326-336. doi:10.1016/j.watres.2016.04.068.

[7] Nitto Denko, Chemical Pretreatment For RO and NF. Technical Application Bulletin No. 111., 2013.

[8] V.T. Do, C.Y. Tang, M. Reinhard, J.O. Leckie, Degradation of polyamide nanofiltration and reverse osmosis membranes by hypochlorite, Environ. Sci. Technol. 46 (2012) 852859. doi:10.1021/es203090y.

[9] B.C. Donose, S. Sukumar, M. Pidou, Y. Poussade, J. Keller, W. Gernjak, Effect of pH on the ageing of reverse osmosis membranes upon exposure to hypochlorite, Desalination. 309 (2013) 97-105. doi:10.1016/j.desal.2012.09.027.

[10] C.J. Gabelich, T.I. Yun, B.M. Coffey, Effects of aluminum sulfate and ferric chloride coagulant residuals on polyamide membrane, Desalination. 150 (2002) 15-30.

[11] Y.-N. Kwon, R. Joksimovic, I.-C. Kim, J.O. Leckie, Effect of bromide on the chlorination of a polyamide membrane, Desalination. 280 (2011) 80-86. doi:10.1016/j.desal.2011.06.046.

[12] A. Simon, L.D. Nghiem, P. Le-Clech, S.J. Khan, J.E. Drewes, Effects of membrane degradation on the removal of pharmaceutically active compounds (PhACs) by NF/RO filtration processes, J. Memb. Sci. 340 (2009) 16-25. doi:10.1016/j.memsci.2009.05.005.

[13] J.-Y. Koo, J.H. Lee, Y.D. Jung, S.P. Hong, S.R. Yoon, Chlorine Resistant Membrane and The Mechanism of Membrane Degradation by Chlorine, Proc. Water Environ. Fed. 14 (2008) 2958-2969.

[14] V.T. Do, C.Y. Tang, M. Reinhard, J.O. Leckie, Effects of chlorine exposure conditions on physiochemical properties and performance of a polyamide membrane-mechanisms and implications, Environ. Sci. Technol. 46 (2012) 13184-13192. doi:10.1021/es302867f. 
[15] V.T. Do, C.Y. Tang, M. Reinhard, J.O. Leckie, Effects of hypochlorous acid exposure on the rejection of salt, polyethylene glycols, boron and arsenic(V) by nanofiltration and reverse osmosis membranes, Water Res. 46 (2012) 5217-5223. doi:10.1016/j.watres.2012.06.044.

[16] J.M. Gohil, A.K. Suresh, Chlorine Attack on Reverse Osmosis Membranes: Mechanisms and Mitigation Strategies, J. Memb. Sci. 541 (2017) 108-126. doi:10.1016/j.memsci.2017.06.092.

[17] A. Ettori, E. Gaudichet-Maurin, P. Aimar, C. Causserand, Pilot scale study of chlorination-induced transport property changes of a seawater reverse osmosis membrane, Desalination. 311 (2013) 24-30. doi:10.1016/j.desal.2012.11.004.

[18] C.Y. Tang, Y.-N. Kwon, J.O. Leckie, Effect of membrane chemistry and coating layer on physiochemical properties of thin film composite polyamide RO and NF membranes: I. FTIR and XPS characterization of polyamide and coating layer chemistry, Desalination. 242 (2009) 149-167. doi:10.1016/j.desal.2008.04\.

[19] A. Thompson, D. Attwoord, E. Gullikson, M. Howells, K.-J. Kim, J. Kirz, J. Kortright, I. Lindau, Y. Liu, P. Pianetta, A. Robinson, J. Scofield, J. Underwood, G. Williams, H. Winick, X-ray Data Booklet, 2009. doi:10.1107/S090904950100807X.

[20] C.Y. Tang, Y.N. Kwon, J.O. Leckie, Probing the nano- and micro-scales of reverse osmosis membranes-A comprehensive characterization of physiochemical properties of uncoated and coated membranes by XPS, TEM, ATR-FTIR, and streaming potential measurements, J. Memb. Sci. 287 (2007) 146-156. doi:10.1016/j.memsci.2006.10.038.

[21] N. Fairley, Lorentzian Asymmetric Lineshape, CasaXPS Softw. (2008) 7. http://www.casaxps.com/help_manual/manual_updates/LA_Lineshape.pdf (accessed September 2, 2017).

[22] M.P. Seah, Simple universal curve for the energy-dependent electron attenuation length for all materials, Surf. Interface Anal. 44 (2012) 1353-1359. doi:10.1002/sia.5033.

[23] M.P. Seah, A system for the intensity calibration of electron spectrometers, J. Electron Spectros. Relat. Phenomena. 71 (1995) 191-204. doi:10.1016/0368-2048(94)02275-5.

[24] D. Briggs, J.T. Grant, Surface Analysis by Auger and X-ray Photoelectron Spectroscopy, , Manchester, 2003, IM Publications, Manchester, 2003.

[25] S. Hofmann, Auger- and X-Ray Photoelectron Spectroscopy in Materials Science, Springer Berlin, Heidelberg, 2013.

[26] I. Horcas, R. Fernández, J.M. Gómez-Rodríguez, J. Colchero, J. Gómez-Herrero, A.M. Baro, WSXM: A software for scanning probe microscopy and a tool for nanotechnology, Rev. Sci. Instrum. 78 (2007). doi:10.1063/1.2432410.

[27] P. Fievet, M. Sbaï, A. Szymczyk, C. Magnenet, C. Labbez, A. Vidonne, A New Tangential Streaming Potential Setup for the Electrokinetic Characterization of Tubular Membranes, Sep. Sci. Technol. 39 (2004) 2931-2949. doi:10.1081/SS-200028652.

[28] E. Idil Mouhoumed, A. Szymczyk, A. Schäfer, L. Paugam, Y.H. La, Physico-chemical characterization of polyamide NF/RO membranes: Insight from streaming current measurements, J. Memb. Sci. 461 (2014) 130-138. doi:10.1016/j.memsci.2014.03.025.

[29] S.J. Tao, Positronium Annihilation in Molecular Substances Positron annihilation in 
opals : Evidence of positronium formation Positronium Annihilation in Molecular Substances, J. Chem. Phys. 56 (1972) 5499-5510. doi:http://dx.doi.org/10.1063/1.1677067.

[30] M. Eldrup, D. Lightbody, J.N. Sherwood, The temperature dependence of positron lifetimes in solid pivalic acid, Chem. Phys. 63 (1981) 51-58. doi:10.1016/03010104(81)80307-2.

[31] T.L. Dull, W.E. Frieze, D.W. Gidley, J.N. Sun, a. F. Yee, Determination of pore size in mesoporous thin films from the annihilation lifetime of positronium, J. Phys. Chem. B. 105 (2001) 4657-4662. doi:10.1021/jp004182v.

[32] J. Algers, P. Sperr, W. Egger, G. Kögel, F. Maurer, Median implantation depth and implantation profile of 3-18 keV positrons in amorphous polymers, Phys. Rev. B. 67 (2003) 12-14. doi:10.1103/PhysRevB.67.125404.

[33] A. Vehanen, K. Saarinen, P. Hautojärvi, H. Huomo, Profiling multilayer structures with monoenergetic positrons, Phys. Rev. B. 35 (1987) 4606-4610. doi:10.1103/PhysRevB.35.4606.

[34] C. Hugenschmidt, G. Dollinger, W. Egger, G. Kögel, B. Löwe, J. Mayer, P. Pikart, C. Piochacz, R. Repper, K. Schreckenbach, P. Sperr, M. Stadlbauer, Surface and bulk investigations at the high intensity positron beam facility NEPOMUC, Appl. Surf. Sci. 255 (2008) 29-32. doi:10.1016/j.apsusc.2008.05.304.

[35] C. Hugenschmidt, C. Piochacz, M. Reiner, K. Schreckenbach, The NEPOMUC upgrade and advanced positron beam experiments, New J. Phys. 14 (2012). doi:10.1088/13672630/14/5/055027.

[36] W. Egger, Pulsed low energy positron system (PLEPS) at the Munich research reactor FRM II.pdf, Phys. Status Solidi. 4 (2007) 3969-3972. doi:10.1002/pssc.200675812.

[37] P. Sperr, W. Egger, G. Kögel, G. Dollinger, C. Hugenschmidt, R. Repper, C. Piochacz, Status of the pulsed low energy positron beam system (PLEPS) at the Munich Research Reactor FRM-II, Appl. Surf. Sci. 255 (2008) 35-38. doi:10.1016/j.apsusc.2008.05.307.

[38] J. Kansy, Microcomputer program for analysis of positron annihilation lifetime spectra, Nucl. Instruments Methods Phys. A. 374 (1996) 235-244.

[39] A. Antony, R. Fudianto, S. Cox, G. Leslie, Assessing the oxidative degradation of polyamide reverse osmosis membrane-Accelerated ageing with hypochlorite exposure, J. Memb. Sci. 347 (2010) 159-164. doi:10.1016/j.memsci.2009.10.018.

[40] Y.N. Kwon, C.Y. Tang, J.O. Leckie, Change of chemical composition and hydrogen bonding behavior due to chlorination of crosslinked polyamide membranes, J. Appl. Polym. Sci. 108 (2008) 2061-2066. doi:10.1002/app.25657.

[41] A. Ettori, E. Gaudichet-Maurin, J.C. Schrotter, P. Aimar, C. Causserand, Permeability and chemical analysis of aromatic polyamide based membranes exposed to sodium hypochlorite, J. Memb. Sci. 375 (2011) 220-230. doi:10.1016/j.memsci.2011.03.044.

[42] Y.N. Kwon, J.O. Leckie, Hypochlorite degradation of crosslinked polyamide membranes. II. Changes in hydrogen bonding behavior and performance, J. Memb. Sci. 282 (2006) 456-464. doi:10.1016/j.memsci.2006.06.004.

[43] G. Zheng, H. Lian, J. Xing, L. Shenz, Chlorination and Oxidation of Aromatic 
Polyamides. 1 . Synthesis and Characterization of Some Aromatic Polyamides, J. Appl. Polym. Sci. 61 (1996) 415-420.

[44] G.D. Kang, C.J. Gao, W.D. Chen, X.M. Jie, Y.M. Cao, Q. Yuan, Study on hypochlorite degradation of aromatic polyamide reverse osmosis membrane, J. Memb. Sci. 300 (2007) 165-171. doi:10.1016/j.memsci.2007.05.025.

[45] J. Xu, Z. Wang, X. Wei, S. Yang, J. Wang, S. Wang, The chlorination process of crosslinked aromatic polyamide reverse osmosis membrane: New insights from the study of self-made membrane, Desalination. 313 (2013) 145-155. doi:10.1016/j.desal.2012.12.020.

[46] Y.N. Kwon, J.O. Leckie, Hypochlorite degradation of crosslinked polyamide membranes. I. Changes in chemical/morphological properties, J. Memb. Sci. 283 (2006) 21-26. doi:10.1016/j.memsci.2006.06.004.

[47] J. Powell, J. Luh, O. Coronell, Bulk Chlorine Uptake by Polyamide Active Layers of Thin-Film Composite Membranes upon Exposure to Free Chlorine: Kinetics and Mechanisms, Environ. Sci. Technol. 48 (2015) 2741-2749. doi:10.1021/acs.est.5b02110.

[48] N. Dam, P.R. Ogilby, On the mechanism of polyamide degradation in chlorinated water, Helv. Chim. Acta. 84 (2001) 2540-2548.

[49] J.C. Vickerman, I.S. Gilmore, Surface Analysis - The Principal Techniques, 2009. http://doi.wiley.com/10.1002/9780470721582.

[50] P. Naumov, Y. Topcu, M. Eckert-Maksić, Z. Glasovac, F. Pavošević, M. Kochunnoonny, H. Hara, Photoinduced rearrangement of aromatic N-chloroamides to chloroaromatic amides in the solid state: Inverted $\Pi n-\Sigma \mathrm{N}$ occupational stability of amidyl radicals, J. Phys. Chem. A. 115 (2011) 7834-7848. doi:10.1021/jp203771c.

[51] C.Y. Tang, Y.-N. Kwon, J.O. Leckie, Effect of membrane chemistry and coating layer on physiochemical properties of thin film composite polyamide RO and NF membranes II. Membrane physiochemical properties and their dependence on polyamide and coating layers, Desalination. 242 (2009) 168-182. doi:10.1016/j.desal.2008.0.

[52] F. Pacheco, R. Sougrat, M. Reinhard, J.O. Leckie, I. Pinnau, 3D visualization of the internal nanostructure of polyamide thin films in RO membranes, J. Memb. Sci. 501 (2016) 33-44. doi:10.1016/j.memsci.2015.10.061.

[53] P.R. Buch, D. Jagan Mohan, a. V.R. Reddy, Preparation, characterization and chlorine stability of aromatic-cycloaliphatic polyamide thin film composite membranes, J. Memb. Sci. 309 (2008) 36-44. doi:10.1016/j.memsci.2007.10.004.

[54] H. Zhang, G.M. Geise, Modeling the water permeability and water/salt selectivity tradeoff in polymer membranes, J. Memb. Sci. 520 (2016) 790-800. doi:10.1016/j.memsci.2016.08.035.

[55] S.T. Mitrouli, A.J. Karabelas, N.P. Isaias, Polyamide active layers of low pressure RO membranes: Data on spatial performance non-uniformity and degradation by hypochlorite solutions, Desalination. $260 \quad$ (2010) 91-100. doi:10.1016/j.desal.2010.04.061.

[56] J.-H. Lee, J.Y. Chung, E.P. Chan, C.M. Stafford, Correlating chlorine-induced changes in mechanical properties to performance in polyamide-based thin film composite 
membranes, J. Memb. Sci. 433 (2013) 72-79. doi:10.1016/j.memsci.2013.01.026.

[57] S.D. Jons, K.J. Stutts, M.S. Ferritto, W.E. Mickols, Treatment of composite polyamide membranes to improve performance, U.S. Patent 5,876,602, 1999. doi:10.1016/S09582118(00)80090-7.

[58] J.-Y. Koo, R.J. Petersen, J.E. Cadotte, ESCA Characterization of Chlorine-damaged Polyamide Reverse Osmosis Membrane, ACS Polym. Prepr. 27 (1986) 391-392.

[59] J. Glater, M.R. Zachariah, S.B. Mccray, J.W. Mccutchan, Reverse osmosis membrane sensitivity to ozone and halogen disinfectants, Desalination. 48 (1983) 1-16.

[60] N.P. Soice, A.R. Greenberg, W.B. Krantz, A.D. Norman, Studies of oxidative degradation in polyamide RO membrane barrier layers using pendant drop mechanical analysis, J. Memb. Sci. 243 (2004) 345-355. doi:10.1016/j.memsci.2004.06.039.

[61] S. Avlonitis, W.T. Hanbury, T. Hodgkiess, Chlorine degradation of aromatic polyamides, Desalination. 85 (1992) 321-334. doi:10.1016/0011-9164(92)80014-Z.

[62] M. Liu, D. Wu, S. Yu, C. Gao, Influence of the polyacyl chloride structure on the reverse osmosis performance, surface properties and chlorine stability of the thin-film composite polyamide membranes, J. Memb. Sci. $326 \quad$ (2009) 205-214. doi:10.1016/j.memsci.2008.10.004.

[63] S.H. Kim, S.Y. Kwak, T. Suzuki, Positron annihilation spectroscopic evidence to demonstrate the flux-enhancement mechanism in morphology-controlled thin-filmcomposite (TFC) membrane, Environ. Sci. Technol. 39 (2005) 1764-1770. doi:10.1021/es049453k.

[64] V.P. Shantarovich, T. Suzuki, C. He, V.W. Gustov, Inhibition of positronium formation by polar groups in polymers - Relation with TSL experiments, Radiat. Phys. Chem. 67 (2003) 15-23. doi:10.1016/S0969-806X(02)00481-4.

[65] G. Consolati, M. Pegoraro, F. Quasso, F. Severini, Chlorinated PTMSP membranes: permeability, free volume and physical properties, Polymer (Guildf). 42 (2001) 12651269. doi:10.1016/S0032-3861(00)00524-3.

[66] K. Hirata, Y. Kobayashi, Y. Ujihira, Effect of halogenated compounds on positronium formation in polycarbonate and polysulfone matrices, J. Chem. Soc. Faraday Trans. 93 (1997) 139-142. doi:10.1039/a605619i.

[67] J. Algers, R. Suzuki, T. Ohdaira, F.H.J. Maurer, Characterization of free volume and density gradients of polystyrene surfaces by low-energy positron lifetime measurements, Polymer (Guildf). 45 (2004) 4533-4539. doi:10.1016/j.polymer.2004.04.008.

[68] A. Cano-Odena, P. Vandezande, K. Hendrix, R. Zaman, K. Mostafa, W. Egger, P. Sperr, J. De Baerdemaeker, I.F.J. Vankelecom, Probing the molecular level of polyimide-based solvent resistant nanofiltration membranes with positron annihilation spectroscopy, J. Phys. Chem. B. 113 (2009) 10170-10176. doi:10.1021/jp9012653.

[69] T. Fujioka, N. Oshima, R. Suzuki, W.E. Price, L.D. Nghiem, Probing the internal structure of reverse osmosis membranes by positron annihilation spectroscopy: Gaining more insight into the transport of water and small solutes, J. Memb. Sci. 486 (2015) 106118. doi:10.1016/j.memsci.2015.02.007.

[70] M. Ding, A. Szymczyk, F. Goujon, A. Soldera, A. Ghoufi, Structure and dynamics of 
water confined in a polyamide reverse-osmosis membrane: A molecular-simulation study, J. Memb. Sci. 458 (2014) 236-244. doi:10.1016/j.memsci.2014.01.054.

[71] M. Mulder, Basic Principles of Membrane Technology. Second edition., 1997. 


\section{Supplementary information}

\section{Real-scale chlorination at pH4 of BW30 TFC membranes and their physicochemical characterization}

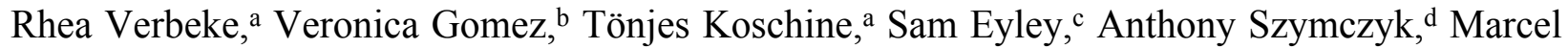
Dickmann, ${ }^{\mathrm{e}}$ Tanja Stimpel-Lindner, ${ }^{\mathrm{f}}$ Werner Egger, ${ }^{\mathrm{g}}$ Wim Thielemans, ${ }^{\mathrm{c}}$ Ivo Vankelecom ${ }^{\mathrm{a}}$

${ }^{a}$ Centre for Surface Chemistry and Catalysis, Faculty of Bioengineering Sciences, KU Leuven, Celestijnenlaan 200F, PO Box 2461, 3001 Leuven, Belgium

${ }^{b}$ Dow Water and Process Solutions, Autovía Tarragona-Salou s/n, 43006 Tarragona, Spain

${ }^{c}$ Chemical Engineering, KU Leuven Campus Kulak Kortrijk, Etienne Sabbelaan 53 box 7659, 8500 Kortrijk, Belgium

${ }^{\mathrm{d}}$ Institut des Sciences Chimiques de Rennes, CNRS, UMR 6226, Université de Rennes 1, 35042 Rennes, France

e Heinz Maier-Leibnitz Zentrum (MLZ) and Physik Department E21, Technische Universität München, Lichtenbergstraße 1, 85748 Garching, Germany

f Institut für Physik, Universität der Bundeswehr München, Werner-Heisenberg-Weg 39, 85577 Neubiberg, Germany

g Institut für Angewandte Physik und Messtechnik, Universität der Bundeswehr München, 85577 Neubiberg, Germany

*Corresponding author at: Centre for Surface Chemistry and Catalysis, Faculty of Bioengineering Sciences, KU Leuven, Celestijnenlaan 200F, PO Box 2461, 3001 Leuven, Belgium.

E-mail address: ivo.vankelecom@kuleuven.be 

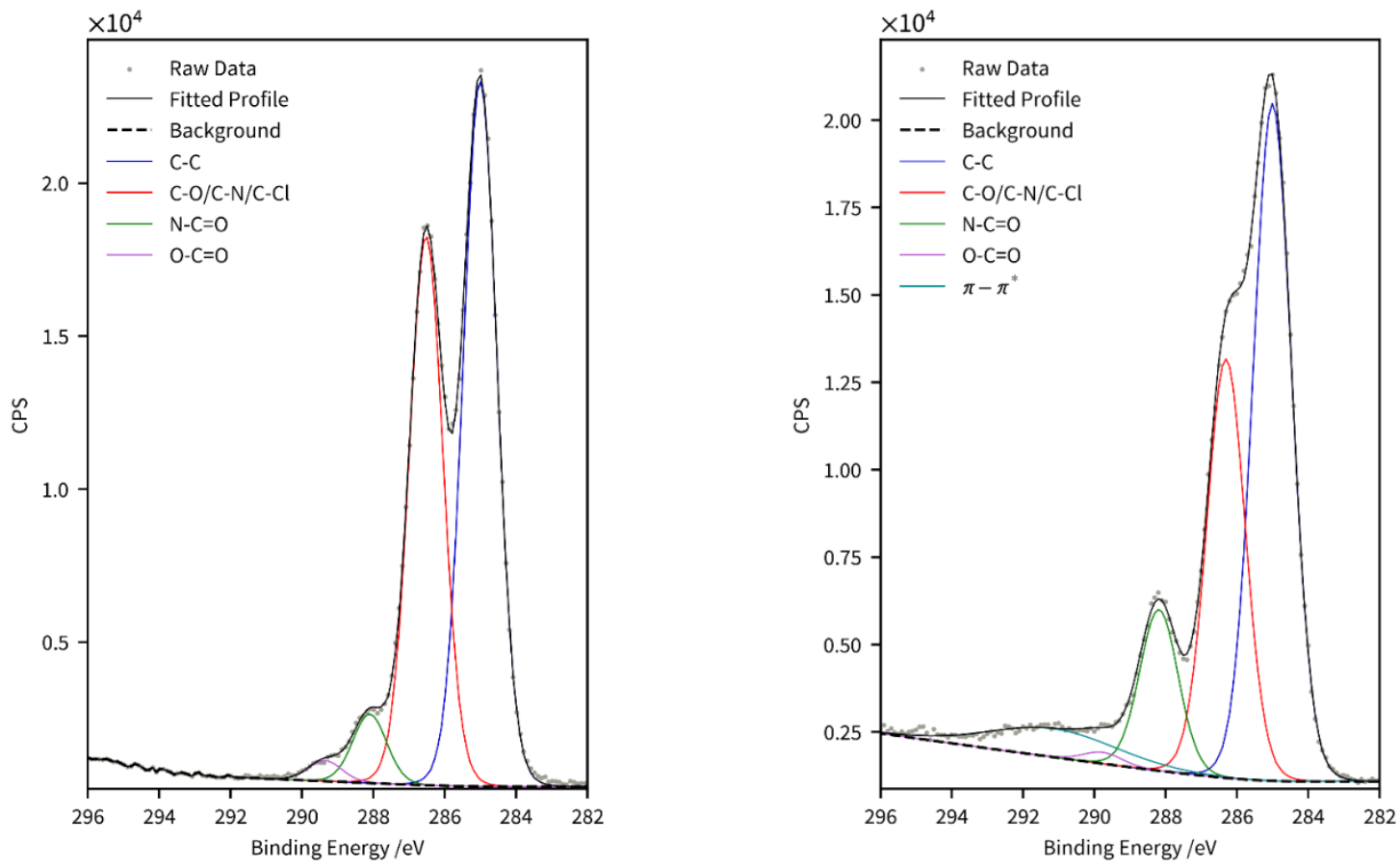

Supplementary Figure 1: Representative C 1s spectra of the reference membrane (0 ppm) (Form A, left) and 50 ppm position 3 (Form B, right). Each carbon 1s spectrum from all five samples can be decomposed into one of two potential forms. Form A consists of a peak at $285.0 \mathrm{eV}$ due to aliphatic carbon, one at $286.5 \mathrm{eV}$ due to $\mathrm{C}-\mathrm{O}$, C-N or C-Cl environments, one at $288.2 \mathrm{eV}$ due to amide environments and one at $289.0 \mathrm{eV}$ to $289.5 \mathrm{eV}$ due to carboxylate environments consistent with the polymer database compiled by Beamson and Briggs [1]. Form B is distinguished by a broad feature at high binding energy due to $\pi-\pi^{*}$ transitions that obscures the carboxylate peak. 

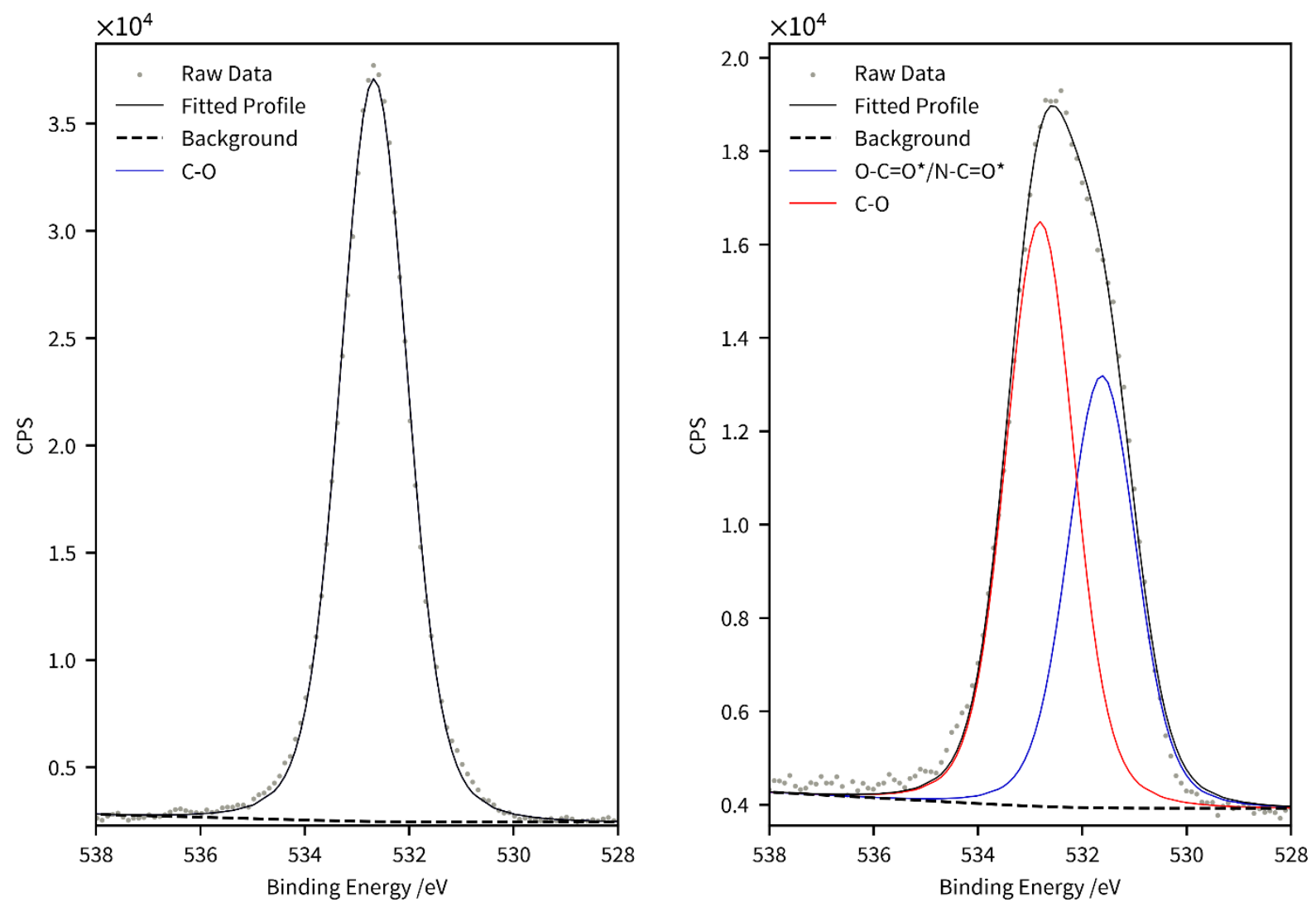

Supplementary Figure 2: Representative oxygen 1s spectra of high coating-content area of the reference membrane (left) and high PA-content area of the $50 \mathrm{ppm}$-membrane (right). 


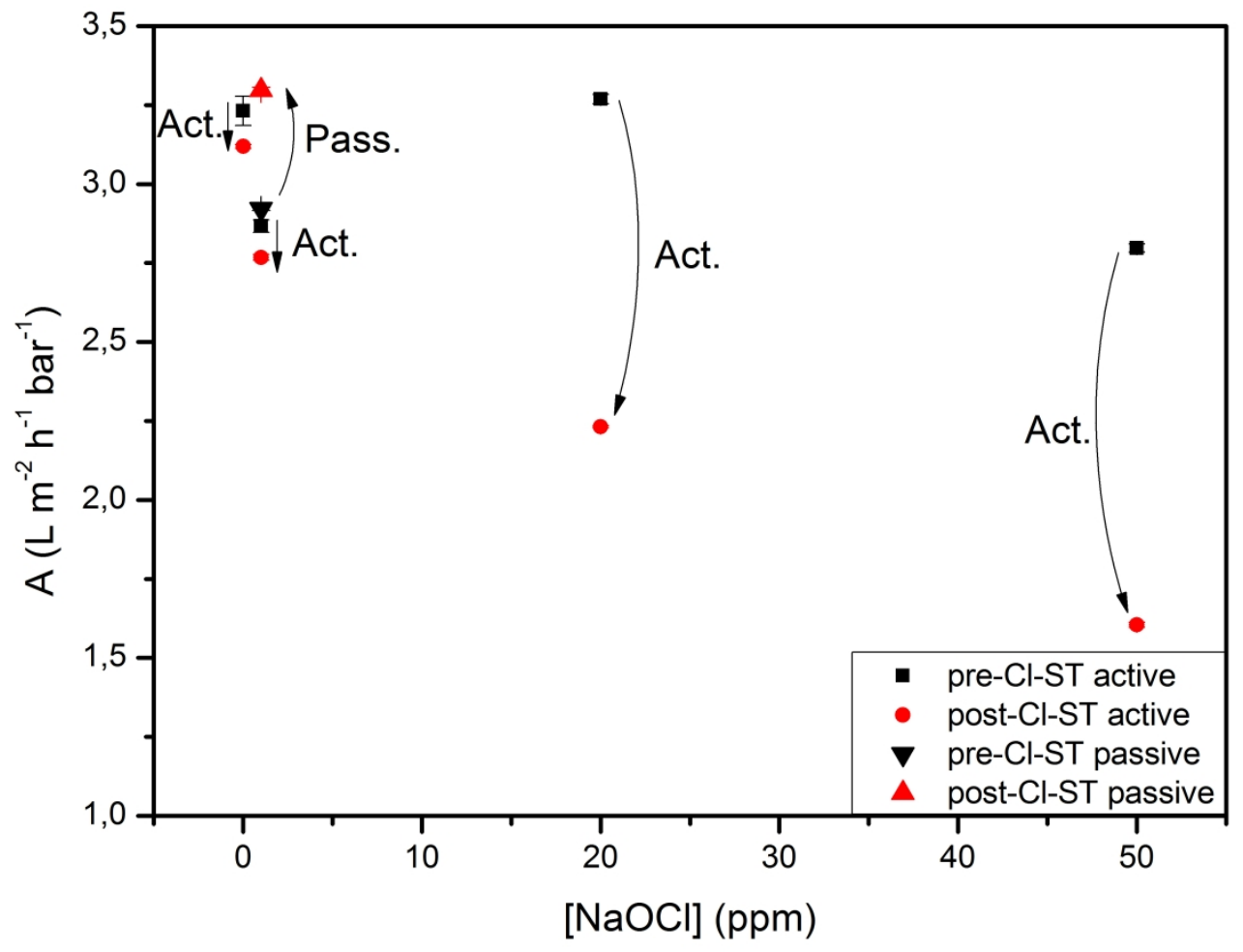

Supplementary Figure 3: Actual A-values of BW30 8" membrane elements during pre-Cl-ST and post-Cl-ST in both active (chlorination at 10 bar) and passive (chlorination via simple immersion at atmospheric pressure). Filtration conditions of standard tests: $\mathrm{NaCl}(2000 \mathrm{ppm})$, iso-propanol $(100 \mathrm{ppm})$ and boric acid $(5 \mathrm{ppm})$ in $\mathrm{RO}$ permeate at $15.5 \mathrm{bar}, 25{ }^{\circ} \mathrm{C}, \mathrm{pH8}$ and a recovery of $15 \%$. The reported standard deviations are based on the online recordings of $Q_{p}$, after reaching steady state, for at least 20 minutes. For most conditions, error bars are hidden by the symbols. 


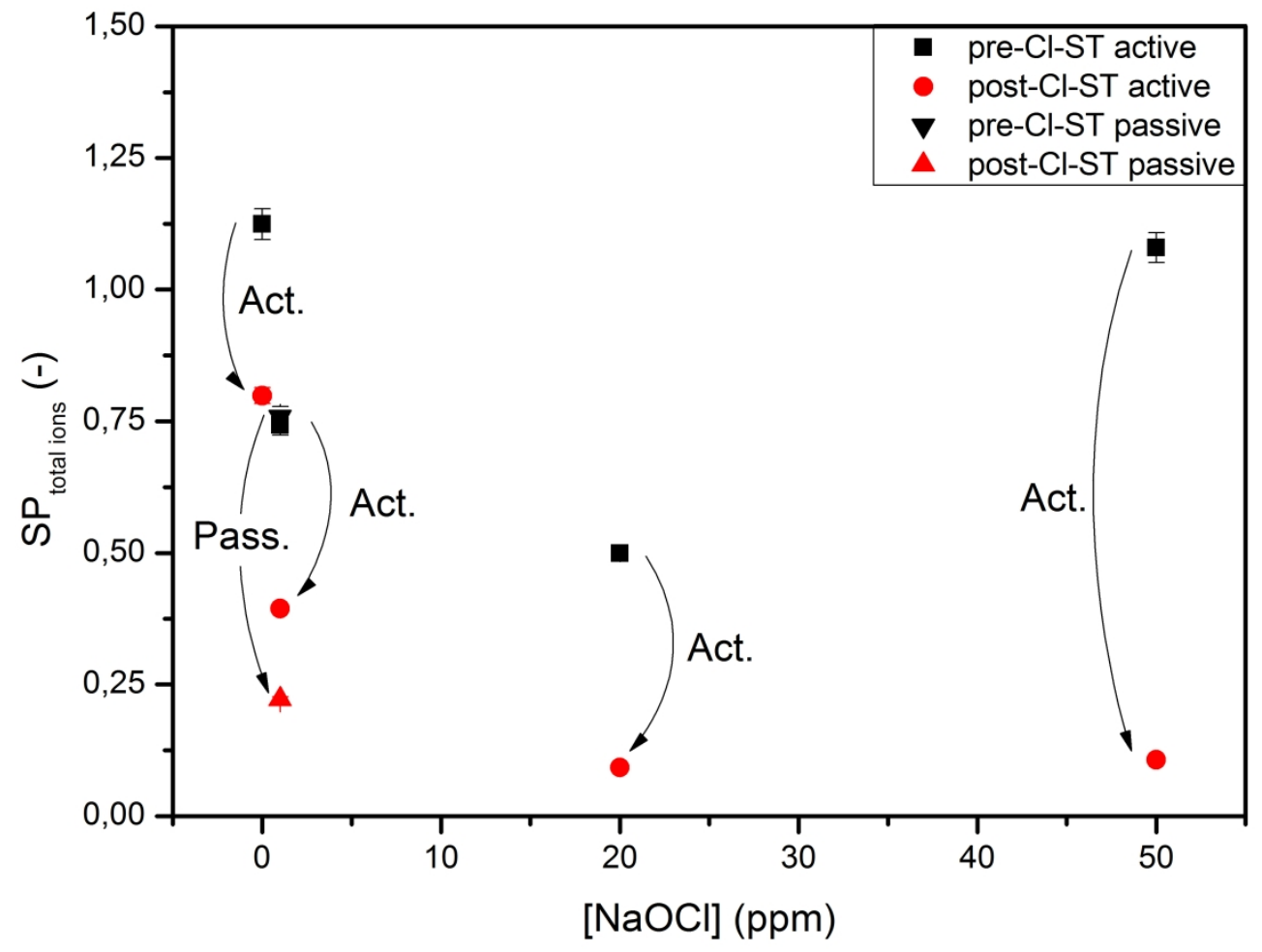

Supplementary Figure 4: Actual SP values of BW30 8" membrane elements during pre-Cl-ST and post-Cl-ST in both active (chlorination at 10 bar) and passive (chlorination via simple immersion at atmospheric pressure). Filtration conditions of standard tests: $\mathrm{NaCl}(2000 \mathrm{ppm})$, iso-propanol $(100 \mathrm{ppm})$ and boric acid $(5 \mathrm{ppm})$ in $\mathrm{RO}$ permeate at $15.5 \mathrm{bar}, 25{ }^{\circ} \mathrm{C}, \mathrm{pH8}$ and a recovery of $15 \%$. SP values are based on total ions and are calculated based on the average values of all ions detected in the feed and permeate water, based on at least 3 replicates. For most conditions, error bars are hidden by the symbols. 


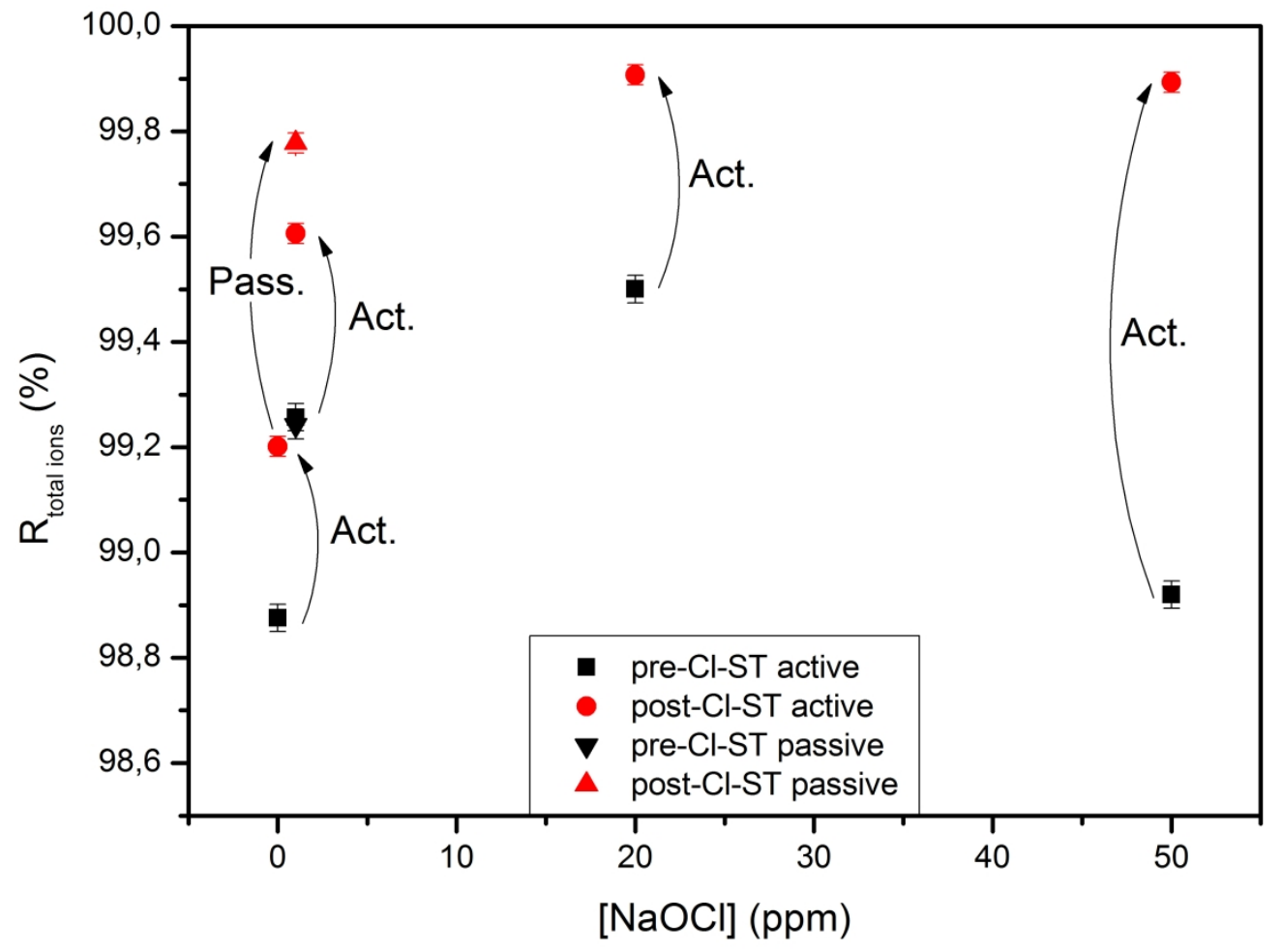

Supplementary Figure 5: Actual rejection values based on total ions of BW30 8" membrane elements during pre-Cl-ST and post-Cl-ST in both active (chlorination at 10 bar) and passive (chlorination via simple immersion at atmospheric pressure). Filtration conditions of standard tests: $\mathrm{NaCl}(2000 \mathrm{ppm})$, iso-propanol $(100 \mathrm{ppm})$ and boric acid $(5 \mathrm{ppm})$ in $\mathrm{RO}$ permeate at $15.5 \mathrm{bar}, 25{ }^{\circ} \mathrm{C}, \mathrm{pH} 8$ and a recovery of $15 \%$. Rejection values are based on total ions and are calculated based on the average values of all ions detected in the feed and permeate water, based on at least 3 replicates. 


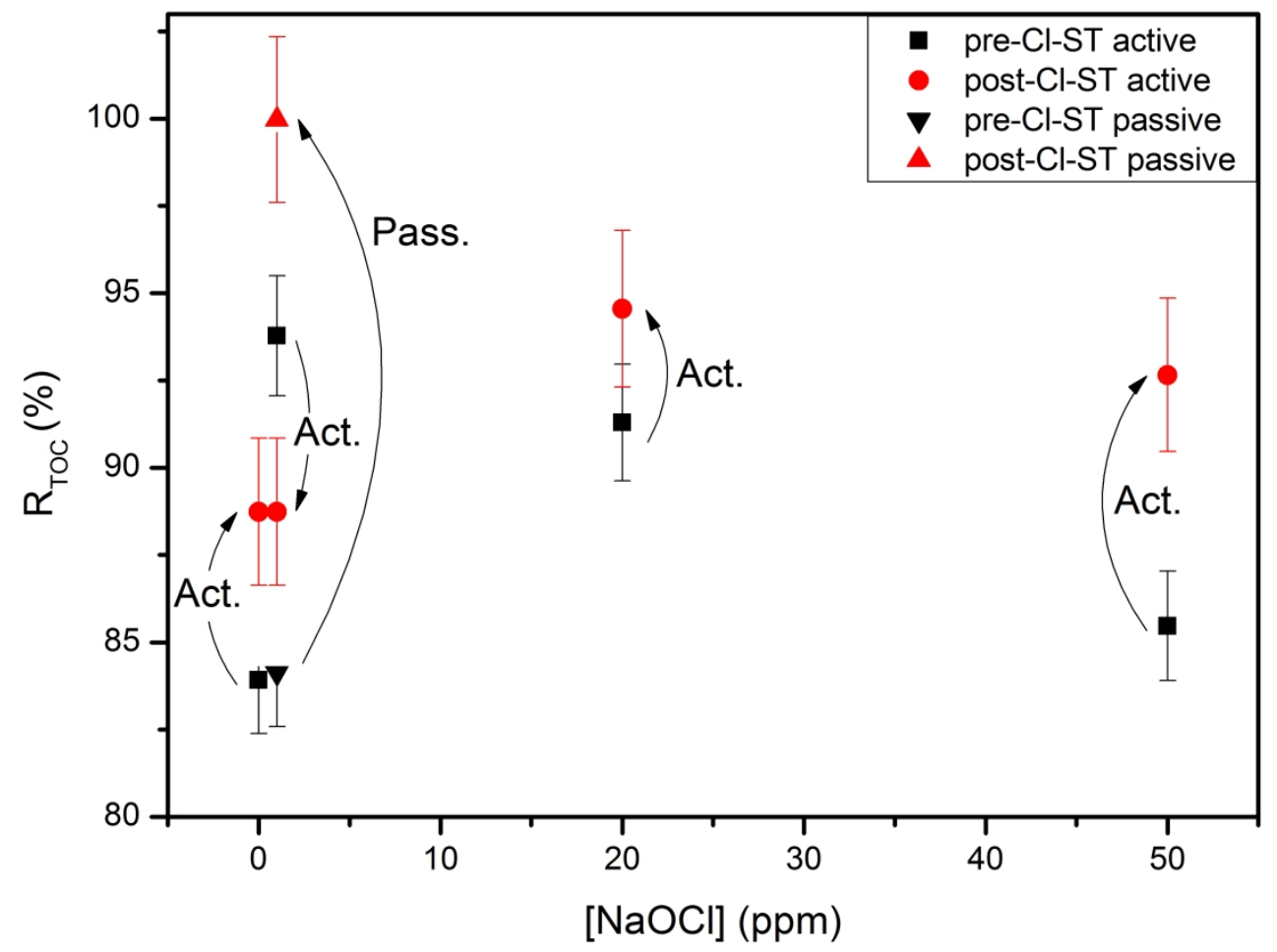

Supplementary Figure 6: Actual rejection values of TOC of BW30 8" membrane elements during pre-Cl-ST and post-Cl$S T$ in both active (chlorination at 10 bar) and passive (chlorination via simple immersion at atmospheric pressure). Filtration conditions of standard tests: $\mathrm{NaCl}(2000 \mathrm{ppm})$, iso-propanol $(100 \mathrm{ppm})$ and boric acid $(5 \mathrm{ppm})$ in $\mathrm{RO}$ permeate at $15.5 \mathrm{bar}, 25^{\circ} \mathrm{C}$, pH8 and a recovery of $15 \%$. Values are based on 3 repetitions. 


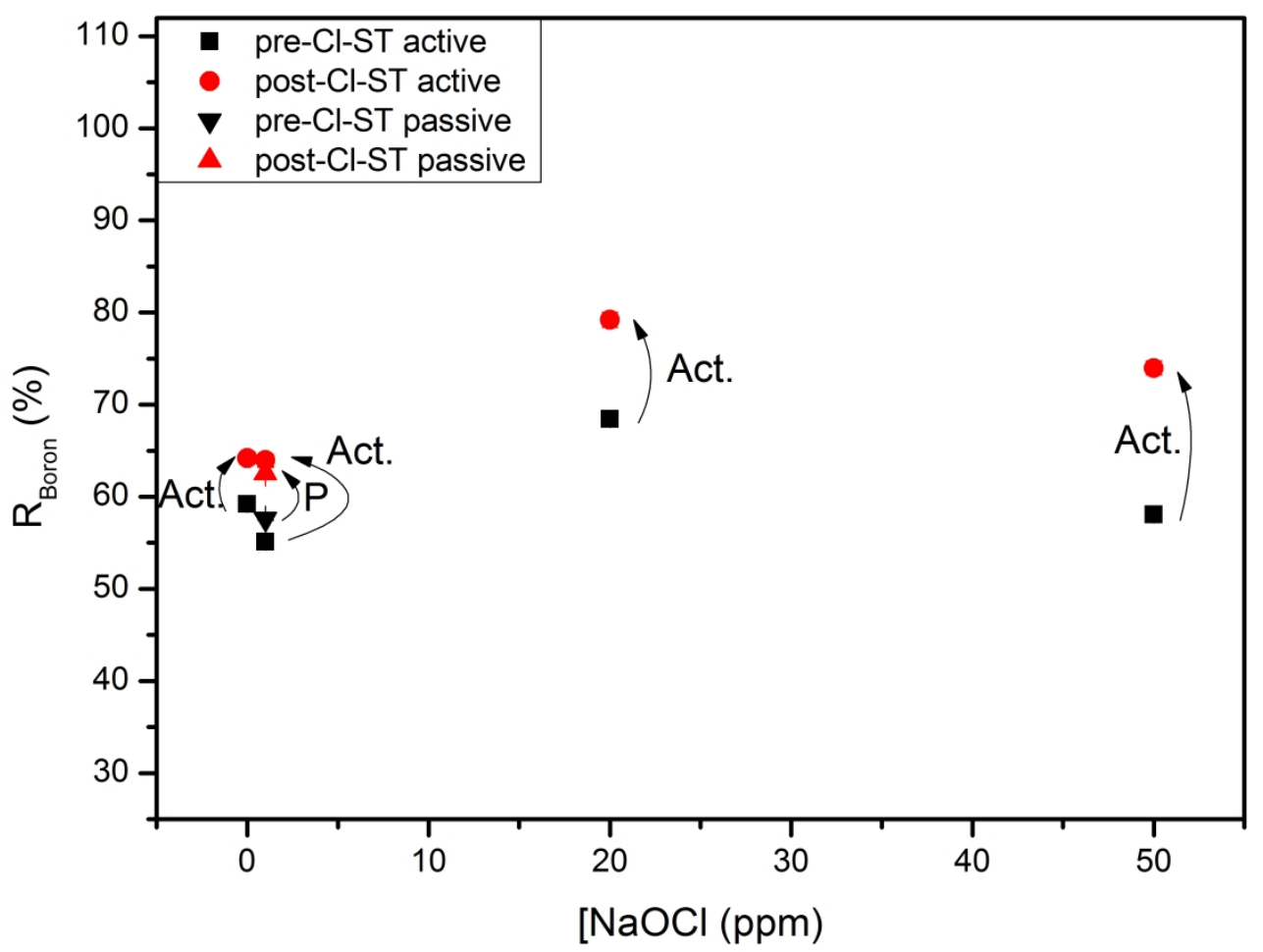

Supplementary Figure 7: Actual rejection values of boron of BW30 8" membrane elements during pre-Cl-ST and post-ClST in both active (chlorination at 10 bar) and passive $(P)$ (chlorination via simple immersion at atmospheric pressure). Filtration conditions of standard tests: $\mathrm{NaCl}(2000 \mathrm{ppm})$, iso-propanol $(100 \mathrm{ppm})$ and boric acid $(5 \mathrm{ppm})$ in $\mathrm{RO}$ permeate at $15.5 \mathrm{bar}, 25{ }^{\circ} \mathrm{C}, \mathrm{pH} 8$ and a recovery of $15 \%$. Values are based on 3 repetitions. For most conditions, error bars are hidden by the symbols.

\section{References}

[1] G. Beamson, D. Briggs, The XPS of Polymers Database, in: Surf. Spectra, Manchester, 2000. 